\title{
Microenvironment, Oncoantigens, and Antitumor Vaccination: Lessons Learned from BALB-neuT Mice
}

\author{
Laura Conti, Roberto Ruiu, Giuseppina Barutello, Marco Macagno, Silvio Bandini, \\ Federica Cavallo, and Stefania Lanzardo
} Department of Molecular Biotechnology and Health Sciences, Molecular Biotechnology Center, University of Torino,
Via Nizza 52, 10126 Torino, Italy

Correspondence should be addressed to

Federica Cavallo; federica.cavallo@unito.it

Received 10 April 2014; Accepted 12 May 2014; Published 3 June 2014

Academic Editor: Zhiqiang Meng

Copyright @ 2014 Laura Conti et al. This is an open access article distributed under the Creative Commons Attribution License, which permits unrestricted use, distribution, and reproduction in any medium, provided the original work is properly cited.

\begin{abstract}
The tyrosine kinase human epidermal growth factor receptor 2 (HER2) gene is amplified in approximately $20 \%$ of human breast cancers and is associated with an aggressive clinical course and the early development of metastasis. Its crucial role in tumor growth and progression makes HER2 a prototypic oncoantigen, the targeting of which may be critical for the development of effective anticancer therapies. The setup of anti-HER2 targeting strategies has revolutionized the clinical outcome of HER2 ${ }^{+}$breast cancer. However, their initial success has been overshadowed by the onset of pharmacological resistance that renders them ineffective. Since the tumor microenvironment (TME) plays a crucial role in drug resistance, the design of more effective anticancer therapies should depend on the targeting of both cancer cells and their TME as a whole. In this review, starting from the successful know-how obtained with a HER2 ${ }^{+}$mouse model of mammary carcinogenesis, the BALB-neuT mice, we discuss the role of TME in mammary tumor development. Indeed, a deeper knowledge of antigens critical for cancer outbreak and progression and of the mechanisms that regulate the interplay between cancer and stromal cell populations could advise promising ways for the development of the best anticancer strategy.
\end{abstract}

\section{Introduction}

Solid tumors are currently considered to be organ-like structures, composed of cancer cells and other cells that support tumor development. While deep understanding of cancer cells has been reached, less light has been shed on the cell populations that make up the tumor microenvironment (TME), as they have been ostracized for several decades and are only now being reappraised as a driving force for tumor pathogenesis. TME is composed of cells-such as inflammatory cells, mesenchymal stem cells (MSCs), endothelial cells (ECs), cancer-associated fibroblasts (CAFs), and adipocytes (CAAs) - and soluble factors, cytokines, and the extracellular matrix (Figure 1) that bidirectionally communicate with cancer cells. This continuous and finely tuned interplay can promote cancer outbreak, sustain tumor development and invasion, defend a tumor from host immunity, foster therapeutic resistance, and provide niches for cancer stem cells (CSCs) and dormant metastases [1]. In this respect, TME is now considered to be a good target for anticancer therapies, as it provides the opportunity to perturb the delicate balance that promotes tumor progression. In fact, similarly to tumor cells [2], TME is now thought of as the source of a broad range of targets, of which the most promising are tumorassociated antigens that play a key role in cancer development and progression, called oncoantigens (OAs) [3]. We have recently classified OAs according to cellular localization [4]: Class I (cancer cell surface antigens), Class II (soluble antigens and antigens expressed in the TME), and Class III (intracellular proteins expressed by cancer cells). They are currently emerging as ideal targets for a very specific anticancer treatment, as demonstrated by several studies in preclinical models [3].

HER2 represents the prototypic Class I OA and is found to be overexpressed in a variety of human cancers [5]. HER2 amplification or overexpression is found in $15-20 \%$ of all 


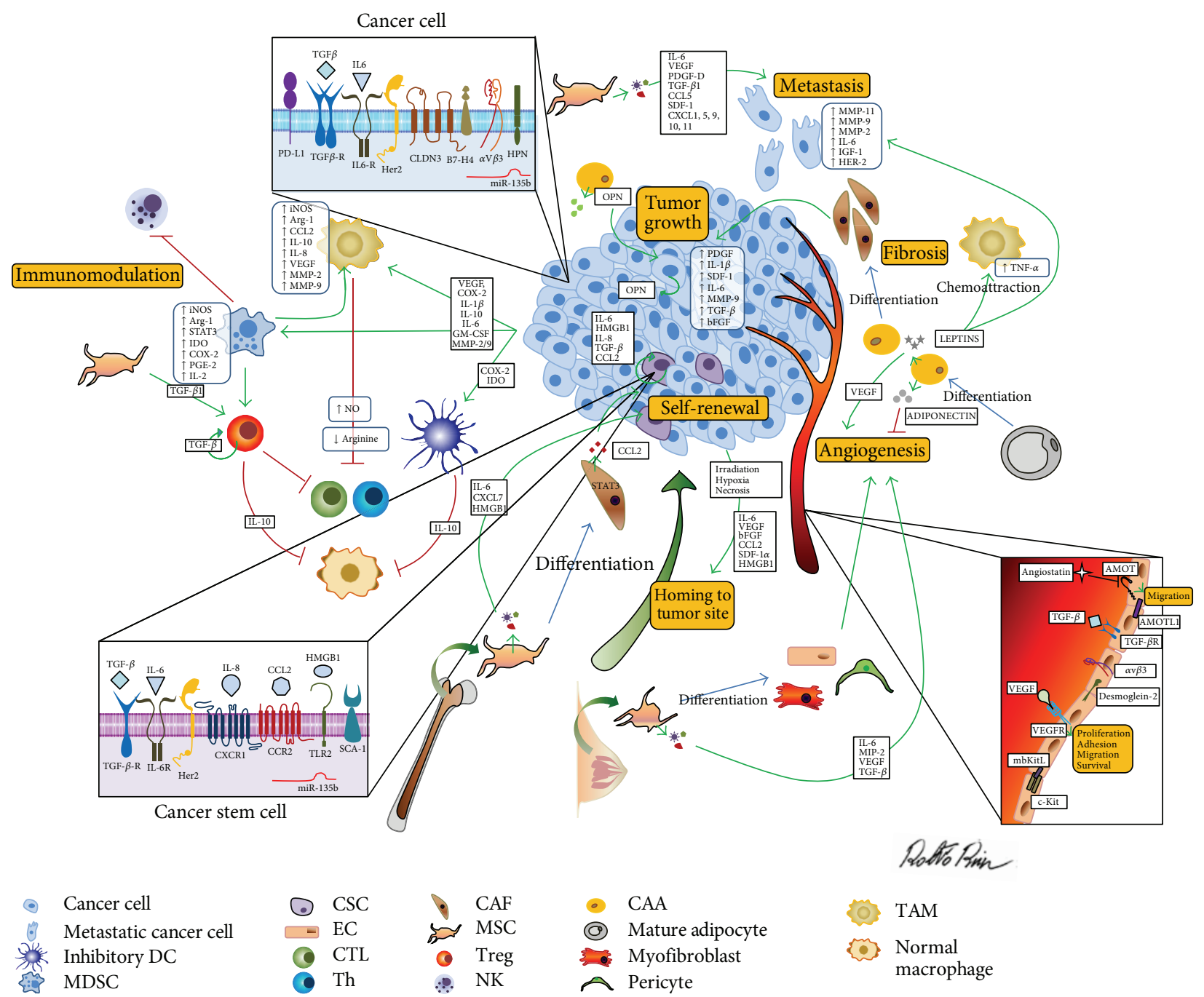

FIGURE 1: Interconnections between the population present in TME in breast tumors. Elevated levels of cytokines and growth factors produced by tumor and stromal cells orchestrate tumor development and progression. Abbreviations: mesenchymal stem cell (MSC), endothelial cell (EC), cancer-associated fibroblast (CAF), cancer stem cell (CSC) adipocyte (CAA), dendritic cell (DC), natural killer (NK), regulatory T (Treg) cell, myeloid derived suppressor cell (MDSC), tumor associated macrophages (TAMs), cytotoxic T lymphocytes (CTL), T helper (Th), interleukin (IL), toll-like receptor (TLR) 2, high mobility group box (HMGB) 1, vascular endothelial growth factor (VEGF), matrix metalloproteinase (MMP), stromal cell-derived factor- (SDF-) 1, transforming growth factor- (TGF-) $\beta$, chemokine (C-C motif) ligand (CCL)2, angiomotin (Amot), angiomotin-like (AmotL) 1, membrane-bound KitL (mbKitL), tumor necrosis factor- (TNF-) $\alpha$, interferon(IFN-) $\gamma$, nitric oxide synthase (iNOS), arginase (Arg) 1, indoleamine-2, 3-dioxygenase (IDO), cyclooxygenase- (COX-) 2, transcription factor signal transducer and activator of transcription (STAT) 3, programmed death (PD) 1, osteopontin (OPN), prostaglandin E- (PGE-) 2, platelet-derived growth factor (PDGF), macrophage inflammatory protein- (MIP-) 2, fibroblast growth factor (FGF), Insulin-like growth factor- (IGF-) 1, and tyrosine kinase human epidermal growth factor receptor (HER) 2.

new breast cancer cases and is a prognostic marker of poor outcome [6]. Currently, the identification of HER2 positivity in tumor tissue specimens allows for patient stratification and a more reasonable therapeutic strategy. Indeed, a number of tyrosine kinase inhibitors or monoclonal antibodies (mAbs) that are directed against HER2 are available, while others are currently under investigation in several phase I to III clinical trials [7]. Humanized mAb Trastuzumab is the standard of care in breast cancer treatment in both preoperatory and metastatic settings, whether it is used as a single agent or in association with chemotherapy. Despite initial responsiveness, the majority of patients that suffer from either primary or metastatic breast cancer develop drug resistance within one year, rendering Trastuzumab completely ineffective [8]. Similarly, prolonged exposition to anti-HER2 tyrosine kinase inhibitors often results in the development of HER-2-negative tumor variants [9]. The mechanisms that underlie primary and acquired resistance to HER2-targeted therapies are still under investigation. However, both CSCs and TME seem to play a crucial role in these phenomena [10]. This fact 
emphasizes the need to consider cancer cells and their TME as a whole when designing effective anticancer therapies and tells us that targeting a single OA is not sufficient to freeze tumor progression, a possibility that can only be explored thanks to the availability of appropriate in vivo cancer models.

The identification of appropriate murine models that are able to mimic most of the features of a human cancer offers considerable potential to give advantages in the race towards the clinic. In particular, the availability of tumortransplantable models and genetically engineered mammary cancer-prone mice has allowed laboratories to decipher the most important mechanisms involved in mammary tumor development and progression, thus permitting current therapies to be refined. A great deal of data has been obtained by our group from transgenic mice, called BALB-neuT, that overexpress the rat HER2 (neu) oncogene under the mouse mammary tumor virus (MMTV) promoter [11], with this very fact in mind. These mice spontaneously develop mammary carcinomas with $100 \%$ penetrance [12] and display a histopathologically [13] and transcriptionally [14] well characterized course that closely recapitulates many features of human breast carcinogenesis. In virtue of the high homology of BALB-neuT tumors to human HER2 positive breast cancer, this is an ideal model to use when setting up new anticancer therapies. Actually, BALB-neuT mice and the cell line derived from a BALB-neuT adenocarcinoma (TUBO cells) have provided us with a fascinating tool and one that is used in many laboratories worldwide to deepen current knowledge of the pathogenic mechanisms that promote HER2 positive tumor growth and consequently elaborate more efficacious antitumor strategies. We herein discuss the lessons learned about TME, HER2, and other OAs from BALB-neuT mice and how this knowledge can help develop a winning strategy against cancer.

\section{The Urgency of Defining the Most Promising TME-Associated OAs}

Neoplastic transformation is a multistep process which involves specific proteins and regulatory pathways at each stage. The identification of the genes that constitute the driving force of cancer progression is an extraordinary opportunity to gain an advantage over cancer. HER2 represents a paradigm of this conception; its expression at the neoplastic stage, its overexpression in established tumors, and its causal role in cancer progression [14] make it the ideal immunological target. This observation has paved the way for the development of new immunologically based therapies against neoplastic cells that overexpress HER2, which have made some important clinical achievements [15]; the U.S. Food and Drug Administration (FDA) has approved mAbs that target HER2, such as Trastuzumab and Pertuzumab, and several drugs (i.e., TDM1 and ARRY380) [16], which have prolonged the disease-free survival rates in patients with metastatic HER2 positive breast cancer [17] and are currently under investigation in clinical trials. However, the majority of patients treated with these agents develop resistance within one year of treatment, resulting in disease progression, recurrence, and reduced overall survival [18]. Similar results have also been obtained using active immunotherapy against HER2 in preclinical models [19]. The efficacy of DNA vaccines targeting HER2 in BALB-neuT mice [20] relies mostly on the direct activity of vaccine-elicited Abs [21-23] and is strictly dependent on the tumor stage at the time of vaccination; the sooner the vaccination is performed, the better the outcome [24]. When the vaccine is administered to a still healthy BALB-neuT mouse, repeated boosts keep it tumor free for a period of time that may well equate to its natural life span. However, when the same vaccine is administered to a mouse in a more advanced stage of microscopic lesions, the appearance of palpable tumors is only slightly delayed. This suggests that targeting a single oncoantigen is not sufficient to freeze tumor progression, especially when it is applied to patients that suffer from advanced cancer, as commonly happens in the clinical setting [12].

This partial failure of anti-HER2 treatment suggests that some key elements that drive mammary carcinogenesis must still be sought out and not only on the tumor cells themselves; the best chance of defeating cancer that we have is offered by targeting both cancer cells and TME. TME can dynamically control cancer progression thanks to its continuous interplay with cancer cells [25]. Therefore, the identification of additional OAs that are expressed by either tumor or stromal cells surrounding HER2 positive lesions is urgently needed if we are to develop a combined and more efficient anticancer approach which may prevent the development of the very resistance to anti-HER2 therapy that is responsible for tumor relapse [26].

To address this point, we performed a transcription profile analysis of BALB-neuT preneoplastic and invasive lesions, integrated with a meta-analysis of data obtained from healthy human and neoplastic specimens. Of the 46 putative OAs identified [27], B7-H4 [28], Claudin 3 [29], Hepsin [30], CD52 [31], and Desmoglein 2 [32] are Class I OAs, expressed on the plasma membrane of cancer and TME cells and therefore constitute promising targets for vaccination. Class II OAs are another group of identified OAs and includes cytokines and chemokines copiously released in the TME. These molecules play important roles in establishing the strictly tuned relationship between tumor and stromal cells whose balance is critical for tumor development and progression, as will be discussed in the following sections of this review. Moreover, this analysis led us to identifying many Class III OAs that belong to signal transduction pathways reported to be deregulated in breast and other cancers, such as mitogen activated protein kinase (MAPK) [33], Survivin [34], Aurora kinase [35], and $s r c$ pathway molecules [36]. It is worth noting that some of these networks seem to be regulatory keys of therapeutic resistance, such as Survivin [37], Topoisomerase II $\alpha$ [38], Desmoglein 2 [39], BCL2interacting killer [40], and ribonucleotide reductase M2 polypeptide [41]. In addition, several identified proteins have a role in CSC self-renewal, which has been demonstrated in the cases of maternal embryonic leucine zipper kinase [42], transcription factor AP-2 $\gamma$ [43], the microtubule associated TPX2 protein [44], and Aurora kinase A [44]. At present, our 
efforts are focused on the characterization of some of these targets and our final goal is the setup of new DNA vaccines that will be tested in BALB-neuT mice in association with anti-HER2 vaccination, in order to improve the vaccination's efficacy against advanced tumor and metastases. A more detailed analysis of OAs that are selectively expressed by the various populations that constitute TME may end up providing us with a sort of tumor Rosetta Stone which could help unveil the reciprocal connection between tumor, CSCs, and stroma.

As reported in several clinical studies, the expression of noncoding genes, such as microRNAs (miRNAs), correlates with cancer relapse and metastasis formation [45]. Several miRNAs contribute to tumor progression in virtue of their ability to posttranscriptionally modulate the expression of oncogenes or oncosuppressors. They can act directly on TME, regulating both the survival of more differentiated cancer cells and the maintenance of a CSC phenotype [46] and controlling neoangiogenesis during tumor progression [47]. Results from experimental studies, which have been strengthened by the human cancer miRNA expression profile, have led researchers to the identification of miRNAs as potent regulators of the crosstalk between cancer and stromal cells [48]. Even if miRNAs cannot be considered oncoantigens because of their lack of immunogenicity, the identification of miRNAs, which are differentially expressed in the tumor, can lead to the identification of their target genes as potential oncoantigens or oncosuppressors, nevertheless [19].

Of note among the miRNAs that have recently been identified is the strong upregulation of miR-135b which has been found in invasive mammary BALB-neuT carcinomas; acting on its targets, midline 1 (MID1) and mitochondrial carrier homolog 2 (MTCH2), it regulates CSC stemness in vitro and cancer cell metastatization in vivo [49]. This newly unveiled role for miR-135b in mammary carcinogenesis, as observed in other tumors such as colon cancer [50], osteosarcoma [51], ependymoma [52], and hepatocellular carcinoma [53], can provide the basis for the exploration of miR-135b, MID1, and MTCH2's potential as new therapeutic targets in mammary carcinogenesis.

\section{CSCs on Stage}

The scientific spotlight has very recently been pointed on CSCs, the subpopulation of cells endowed with self-renewal potential and refractoriness to chemo- and radiotherapy that are capable of sustaining tumor growth and progression by giving rise to the heterogeneous population of tumor cells found within a tumor [54]. Even though the initial idea of CSCs as static entities [55] has been overtaken [56], it is well accepted that they control cancer development and progression in a manner that is guided by environmental factors [57]. CSCs are thought to reside in a highly specialized niche that is made up of stromal, endothelial, and more differentiated tumor cells that stimulate CSC survival and stemness via cell to cell contact, paracrine, and other signals [58]. A central role is played here by interleukin- (IL-) 6, which is produced by CSCs and noncancerous cells, MSCs, and immune cells.
IL-6 promotes CSC self-renewal, the recruitment of MSCs and immune cells, and the preservation of an inflammatory state that favors tumor growth. Moreover, IL-6 promotes the conversion of more differentiated tumor cells into CSCs, inducing the epithelial-to-mesenchymal transition (EMT). Recently, it has been shown that HER2 overexpression in breast CSCs increases IL-6 secretion [59] which is involved in Trastuzumab resistance [60].

We have recently demonstrated that an autocrine loop involving toll-like receptor $2 /$ high mobility group box$1 / \mathrm{NF} \kappa \mathrm{B}$ (TLR2/HMGB1/NF $\kappa \mathrm{B}$ ) induces the enhanced secretion of vascular endothelial growth factor (VEGF) and IL6 in $\mathrm{Scal}^{+}$[61] CSCs, derived from BALB-neuT TUBO cells, that in turn activates the transcription factor signal transducer and activator of transcription 3 (STAT3), thus promoting CSC self-renewal [62]. This pathway also induces the secretion of transforming growth factor- (TGF-) $\beta$, a cytokine that induces EMT and the secretion of matrix components that favor metastatization [63]. Moreover, TGF$\beta$ recruits endothelial cells and promotes their proliferation, enhancing angiogenesis [64]. Therefore, HER2 positive CSCs promote their own self-renewal, by upregulating TLR2 and secreting its endogenous ligand HMGB1, and generate a favorable microenvironment for tumor progression. This is a very important observation since HMGB1 is not only secreted by CSCs but also secreted by activated dendritic cells (DCs) [65] and necrotic cells [66] and thus is one of the most important molecules driving tumor escape from cytotoxic treatment.

IL-6 stimulates CSCs, MSCs, and fibroblasts and causes them to secrete IL-8, another key cytokine that promotes CSC self-renewal. It is worth noting that HER2 positive CSCs overexpress IL-8 receptors CXCR1/2 [67], which in turn induce HER2 phosphorylation and the activation of its downstream signaling pathway, generating a positive feedback mechanism that promotes CSC expansion [68]. The inhibition of CXCR1, either by mAbs or specific inhibitors, reduces CSC self-renewal, induces cell apoptosis, and inhibits metastatization in breast cancer, indicating that this receptor may be a promising target for combined anticancer therapies [69]. Similar IL-6-dependent upregulation is observed in the chemokine (C-C motif) ligand (CCL) 2 (also known as monocyte chemotactic protein-1, MCP-1), whose production is induced by IL- 6 in both tumor cells and stromal cells and that supports the expansion of the CSC compartment by activating the Notchl signaling pathway [70]. We demonstrated, by microarray analysis, that CCL2 expression increases in BALB-neuT mice as carcinogenesis progresses [71], and its causal role in cancer development was further supported by the observation that BALB-neuT mice, which were knockedout $(\mathrm{KO})$ for CCL2, displayed prolonged survival over BALBneuT mice wild-type (WT) for this chemokine [72].

The characterization of all the cytokine networks that connect CSCs, tumor cells, and stromal cells may pave the way for new therapeutic strategies and provide diagnostic and prognostic markers for patients. In this regard, many clinical studies have shown that high serum levels of IL8 and IL-6 correlate with poor prognosis in breast cancer 
patients $[73,74]$. Therefore, the design of specific cytokine receptor inhibitors and the assessment of their efficacy in clinical settings may be a source of great potential for future research.

\section{Fighting against Proangiogenic OAs}

Vascular ECs thoroughly govern angiogenesis, a process that supports the growth of many kinds of solid tumors including breast cancer, providing nutrients and oxygen to proliferating cells, thereby allowing cancer cells to invade tissues and develop metastases. Tumor cells have been observed to preferentially align towards and associate with ECs, even prior to the angiogenic switch [75]. Thanks to this strategic tidiness, ECs and tumor cells can bidirectionally communicate through a complex network of both soluble and insoluble signaling molecules that drive cellular differentiation and find ways to foster the tumor. Moreover, ECs are the most important interface between circulating blood cells, tumor cells, and extracellular matrix and play a pivotal role in controlling leukocyte recruitment and tumor cell behavior during angiogenesis.

A great deal of effort has been poured into attempts to block tumor angiogenesis. In this respect, VEGF-A is nowadays the most renowned therapeutic target. The interaction between VEGF ligands and their EC expressed receptors stimulates angiogenesis and promotes EC permeability, survival, migration, and the invasive potential of cancer cells [76]. Bevacizumab is a recombinant humanized $\mathrm{mAb}$ developed against VEGF-A [77], which has been broadly studied in phase III clinical trials and is now FDA-approved for the treatment of metastatic colorectal cancer, nonsmall cell lung cancer, and breast cancer [78]. Other drugs that inhibit the tyrosine kinase activity of VEGFRs, like sunitinib [79], sorafenib [80], axitinib [81], pazopanib [82], vandetanib [83], cabozantinib [84], tivozatinib [85], and linifanib [86], have been developed. Sorafenib has been approved for the treatment of unresectable hepatocellular carcinoma and advanced renal cell carcinoma (RCC), whereas sunitinib has been approved for the treatment of gastrointestinal stromal tumors and metastatic RCC, but only modest benefit has been observed in other types of cancer [87].

Despite many steps forward in the setup of antiangiogenic protocols being made, the development of tumor resistance and the occurrence of relapse in a high percentage of patients have prompted clinicians and researchers to join forces and find new targets for the development of more efficacious therapies. For these reasons, the immune-targeting of OAs expressed on ECs seems to be a successful direction to move towards. As described below, we have tested various DNA vaccination strategies that target tumor angiogenesis; all these vaccines have demonstrated high efficacy without any toxic effect, further stressing the therapeutic potential of targeting tumor ECs in HER2 positive tumors.

Of the class II OAs found to be overexpressed in tumor ECs during BALB-neuT cancer progression [88], the most promising is angiomotin (Amot), a member of the Motin protein family. Using a construct that encodes the kringle domains 1-4 of angiostatin to screen a yeast two-hybrid placenta cDNA library for angiostatin-binding peptides [89], Amot was originally identified as one of the angiostatin receptors. Amot is normally expressed on ECs, where it exerts its proangiogenic activity and stimulates EC migration during angiogenesis [90]. Amot is overexpressed compared to normal tissues in human breast tumors and its presence correlates with poor prognosis and metastatic disease [90]. These findings suggest that Amot has an important role to play during breast tumor progression and may be an optimal target for anticancer therapy [91]. In virtue of these features, we decided to elicit an immunological response against Amot, by means of DNA vaccination, in mice that bear microscopic invasive mammary cancers. This strategy was successfully applied in BALB-neuT mice as well as in the PyMT mouse model of breast cancer, in which carcinogenesis is driven by the polyoma middle $\mathrm{T}$ oncoantigen [92]. The therapeutic effect of anti-Amot vaccination was mediated by the induction of specific antibodies that induced increased tumor vessel permeability, which, in turn, resulted in both an increase in chemotherapy efficacy and major epitope spreading, which was accompanied by the induction of a specific anti-HER 2 antibody response that further contrasted tumor growth [93].

Another member of the Motin family, angiomotin-like 1 (AmotL1), is an attractive target for antitumor interventions. AmotL1 is endowed with proangiogenic properties that affect EC polarization, directional migration, and the stability of tight junctions during angiogenic sprouting; it may compensate for the absence of Amot and vice versa [94]. Even though our preliminary data indicate that DNA vaccination against AmotLl is not effective in the prevention of mammary tumor appearance in BALB-neuT mice, encouraging data have come from a combined DNA vaccine against HER2 and AmotL1. Even more promising results have been obtained using a combined DNA vaccine against HER2, Amot, and AmotL1 (Barutello G et al., unpublished data). This kind of vaccination exploits the synergistic effect which stems from the combined action of antibodies which target both the ECs of neoformed tumor vessels and the tumor cells themselves.

Membrane-bound KitL (mbKitL), which is involved in the c-Kit/KitL system required for tumor angiogenesis [95], is an additional promising target for antiangiogenic cancer immunotherapy. mbKitL is expressed on tumor ECs and is essential for providing them with survival signals, as is clearly exploited in the role that $\mathrm{c}$-Kit signaling network plays in maintaining breast cancer cells [96]. A DNA vaccine that targets mbKitL is able to inhibit the growth of a mouse HER2 positive transplantable tumor; vaccination impairs tumor vessel formation and stabilization and thus interferes with tumor cell-derived VEGF bioavailability [97].

Besides representing good targets for anticancer therapies, antigens expressed on tumor ECs may also be exploited for tumor diagnosis. In this context, we have recently demonstrated that both ECs and cancer cells in mammary tumors arising in BALB-neuT mice express $\alpha_{v} \beta_{3}$ integrin, a receptor for several extracellular matrix proteins which harbor an arginine-glycine-aspartic acid (RGD) sequence [98]. $\alpha_{v} \beta_{3}$ integrin is widely considered to be a marker of 
the angiogenesis, tumor progression, and invasion of different types of cancer. Since its level of expression correlates with cancer progression [99], we have developed a probe for the optical imaging detection of $\alpha_{v} \beta_{3}$ integrin and have shown that it can successfully detect microscopic in situ carcinomas in BALB-neuT mice, therefore proving itself to be a promising tool for the early diagnosis of breast cancer [98].

\section{The Controversial Role of Inflammation and Immune Cells in the TME}

Despite the fact that natural immune surveillance mechanisms are activated during the early stages of BALB-neuT carcinogenesis [100-103], tumors finally acquire the three immune hallmarks required to progress: the ability to thrive in a chronically inflamed TME, to suppress immune reactivity, and to evade immune recognition [104]. The fight between natural immune surveillance mechanisms and these acquired capabilities is mirrored by the important, yet controversial, role that immune cell infiltrates play in the TME. The tumor stroma of BALB-neuT mice is infiltrated by CD4 and CD8 T lymphocytes and a few B, natural killer (NK), and $\gamma \delta \mathrm{T}$ lymphocytes, but mostly by regulatory $\mathrm{T}$ (Tregs) cells, myeloid derived suppressor cells (MDSCs), and tumor associated macrophages (TAMs) that are recruited into TME in response to inflammatory molecules and cytokines being released in the tumor milieu $[105,106]$.

The acquired ability of BALB-neuT tumors to thrive in a chronically inflamed microenvironment has been highlighted by microarray analyses that have shown the occurrence of an upregulation in four transcriptional networks, in advanced as compared to preneoplastic lesions, whose hub genes code for proinflammatory cytokines IL- $1 \beta$, tumor necrosis factor- (TNF-) $\alpha$, interferon- (IFN-) $\gamma$, and CCL2 [71]. The final outcome of the activation of these four networks is tumor promotion; however, how each individual network influences tumor progression is neither simple nor unequivocal. For instance, increased IFN- $\gamma$ release in TME during tumor progression appears to play a major tumor inhibitory role and is a marker of the M1 TAMs that express immunostimulatory, antiangiogenic, and tumoricidal functions [107]. Accordingly, IFN- $\gamma$ KO BALB-neuT mice display faster tumor progression, associated with a more intense tumor angiogenesis $[71,108,109]$. Moreover, chronic systemic administration of recombinant IL-12 in BALB-neuT mice induced high and sustained IFN $-\gamma$ production, as detected in the sera of treated mice that in turn caused a delay in tumor onset and a reduction in the number of mammary glands affected by the tumor $[109,110]$. The role that the other three networks play in tumor progression is the opposite. They can initially show antitumor activity, but the incipient tumor soon uses them to provide itself with a shortcut for progression. In reality, the activation of CCL2 is directly associated with enhanced progression [72], as discussed above. Similarly, increases in IL- $1 \beta$ and TNF- $\alpha$ in TME may favor cancer progression either directly $[71,111]$ or by recruiting suppressor cells $[112,113]$.
A tumor's ability to exploit inflammation to its own benefit is strictly related to the second immune hallmark of cancer, the capability to suppress the immune response directly or via the recruitment of suppressor cells [104]. IL-1 $\beta$ released by stromal cells together with other tumorderived factors, including granulocyte macrophage colonystimulating factor (GM-CSF), cyclooxygenase 2 (COX-2), IL6 , and VEGF, induce the accumulation and expansion of MDSCs $[112,113]$ by triggering Janus kinase (JAK)/STAT3 pathways [114]. MDSCs are a phenotypically heterogeneous population with an immunosuppressive capacity that are, in normal conditions, generated from the bone marrow and rapidly differentiates into mature DCs, macrophages, or granulocytes, while, in cancer bearing patients, present a partial block of maturation [115]. In BALB-neuT tumors, VEGF was detected in the supernatant from primary tumor cultures and from tumor cell lines as well as in the sera of BALB-neuT tumor-bearing mice. A possible explanation may lie in the increase of matrix metalloproteinase-(MMP-) 9 within the tumor mass, as previously shown [116], that mediates the release of growth factors, such as VEGF, stromal cell-derived factor- (SDF-) 1, and mbKitL [117]. Accordingly, any interference with VEGF or mbKitL activity, besides hampering the angiogenic process $[97,118]$, has been reported to induce MDSC shrinkage [97, 119].

MDSCs exhibit immunosuppressive functions that occur via multiple mechanisms, such as inducible nitric oxide synthase (iNOS) and arginase-1 (Arg-1) production, which suppresses the T-cell immune response in TME via the release of nitric oxide and reactive oxygen species that cause $\mathrm{T}$ cell receptor (TCR) nitration and $\mathrm{T}$ cell apoptosis and the depletion of $\mathrm{L}$-arginine required for $\mathrm{T}$ cell functions [120]. As indoleamine-2, 3-dioxygenase (IDO) appears to be involved in MDSC-mediated T cell inhibition [121] and cyclooxygenase- (COX-) 2 is required to induce, via prostaglandin E- (PGE-) 2, Arg-1 expression by MDSCs $[122,123]$, a considerable amount of effort is going into inhibiting these molecules [124]. In this respect, we are testing a therapeutic protocol that consists of the concomitant administration of anti-HER2 DNA vaccines and plasmids that code for IDO [125] or COX-2 or short hairpin (sh)RNAs in BALB-neuT mice [24].

In order to curb the significant MDSC contribution to suppressing the immune system, we have looked for additional targets that these cells express both in tumor bearing mice and in cancer patients. As discussed above, B7-H4, a member of the B7 family, has been identified as being overexpressed in BALB-neuT mouse invasive lesions and appears to be an excellent target candidate, thanks to its critical role in the regulation of antigen specific immune responses [3]. Indeed, within TME, the expression of B7$\mathrm{H} 4$ by tumor cells and MDSCs seems to be involved in the inhibition of the $\mathrm{T}$ cell response to tumor associated antigens [126]. In the light of these considerations, we are developing DNA plasmids that code for both HER2 and B7H4 shRNAs, and we propose an evaluation of their efficacy in the inhibition of mammary carcinogenesis (Macagno M, unpublished data). Another important pathway that contributes to tumor mediated immune suppression is found in 
the CD28 family member, programmed death 1 (PD-1) and its ligand PD-L1 [127]. PD-L1 is expressed by both MDSCs and tumor cells [128] and its interaction with activated $\mathrm{T}$ cell expressed $\mathrm{PD}-1$ promotes $\mathrm{T}$ cell tolerance by suppressing their cytotoxic capacity and cytokine secretion [127]. We were among the first to show that the PD-1 blockade results in an increased response to antitumor vaccination. In these experiments BALB-neuT mice were vaccinated against HER2 and concomitantly treated with the administration of antiPD-1 mAb BAT [129].

In response to IL- $1 \beta$ stimulation, MDSCs also produce the suppressive cytokine IL-10 [130] which acts on TAMs inducing their reprogramming and polarization towards an M2 phenotype. M2 TAMs support tumor progression through the release of immunosuppressive (i.e., CCL2 and IL10), proangiogenic (i.e., IL-8 and VEGF), and tissue remodeling (i.e., MMP-2 and MMP-9) factors. Their expansion in breast cancer tissues has been correlated with poor prognosis [131]. In BALB-neuT mice M2 TAMs are the main tumor infiltrating population [105]. The administration of zoledronic acid to BALB-neuT mice can revert M2 polarization by interfering with the mevalonate pathway and thus hamper IL10 and VEGF production, recovering the release of IFN $-\gamma$ in the mammary glands of treated mice [105].

HER2 and the other OAs expressed by mammary tumors in BALB-neuT mice are self-molecules toward which the immune system is tolerant [132]. As a consequence, the predominant effector T-cells in the TME are presumably constituted of low avidity OA-specific $\mathrm{T}$ cells whose activity is inhibited by Tregs that first expand in the spleen and tumor draining lymph nodes during cancer progression and in TME in later phases $[100,132,133]$. This situation reproduces what normally happens in tumor bearing patients [134] and is part of the ability to suppress immune reactivity that the tumor acquires during progression [104]. Indeed, natural immune surveillance somehow counteracts Treg expansion in the early phases of carcinogenesis in BALB-neuT mice. In complement C3 KO BALB-neuT mice, tumor progression occurs earlier and this is associated with the increased expansion of Treg cells over complement competent BALBneuT mice [102]. This increased Treg expansion is prompted by a lack of $\mathrm{C} 3 \mathrm{a}$ and $\mathrm{C} 5 \mathrm{a}$, whose receptor signaling is required during the early events of effector $\mathrm{T}$ cell activation [135] and negatively modulates Treg function by inducing FoxP3 downregulation [136]. Its absence in BALB-neuT C3 KO mice deflects naïve $\mathrm{T}$ cells into Treg [137] and potentiates their function [136].

The down modulation of MHC class I (MHC I) [138] is the mechanism most frequently exploited by tumor cells to escape from immune recognition [139]. It is intriguing that an inverse correlation exists between HER2 overexpression and the expression of MHC I and of the components of the antigen-processing machinery [140]. MHC I down modulation, albeit incomplete, means that cancer cells are more susceptible to NK cell-mediated lysis, if NK receptor activating ligands are present. This may have an impact on cancer progression at least in the initial stages of carcinogenesis. The fundamental role that NK cells play in hampering the expansion of incipient BALB-neuT tumors has been investigated in perforin (PFP) KO BALB-neuT mice, as the majority of NK mediated protection relies on the release of PFP on target cells. In fact, both female [103] and male [141] BALB-neuT PFP KO mice show fourfold increases in mammary carcinoma incidence. Nevertheless, preliminary results also indicate that advanced BALB-neuT tumors downregulate the expression of ligands that activate NK receptors (Lanzardo S, unpublished data), suggesting that advanced tumors reach a balance between a loss of sensitivity to $\mathrm{CD}^{+} \mathrm{T}$ cell killing and the maintenance of NK-cellinhibitory specificities. We are now evaluating the expression of MHC I and of some NK ligands in TUBO-derived CSCs to assess whether NK cells recognize and more efficiently kill CSCs than their differentiated counterparts, as has already been shown for colon cancer-derived CSCs [142].

\section{Role of Adipocytes and Fibroblasts in Breast Cancer Progression}

While immune cells are well recognized as major players in the orchestration of a permissive TME, other cell populations have only recently been recognized as active parts of the tumor promoting ability of TME. These include CAAs and FACs.

Besides its classical definition as a fat reservoir, adipose tissue is now considered to be a fully functioning endocrine organ [143] that secretes growth factors and cytokines, known as adipokines, which are involved in angiogenesis, immunity, and endocrine signaling [144]. Adipocytes enshroud the mammary gland, regulating epithelial cell growth during the hormonally controlled courses of mammary gland development, from pubertal maturation to involution after lactation [145].

The understanding of the important, but still underestimated, role of adipocytes in cancer stems from several studies which highlight the anatomical proximity of many tumors to adipose tissues and point to the positive correlation between obesity and higher cancer risk [146-149]. Adipocytes can, under the pressure of cancer cell stimuli, abdicate their physiological role in favor of tumor promoting activities in breast cancers that grow in an adipose tissue dominated context. In this way they become CAAs that exhibit decreased lipid content, reduced adipocytes marker expression, and an overexpression of proinflammatory cytokines and MMPs, such as MMP-11 and MMP-9 $[150,151]$. It is worth noting that MMP-9 has been identified as being overexpressed in BALB-neuT mammary cancer which would seem to point to its important role during tumor progression.

A number of studies have shown that CAAs support and expedite breast cancer progression [152-154] by providing proinflammatory cytokines, such as IL- 6 , TNF- $\alpha$, and reactive oxygen species [155]. On the other hand, IL-6 in breast TME seems to stimulate the proinvasive effects of CAAs, besides promoting CSC self-renewal as discussed above [150]. Moreover, CAAs in TME can differentiate in fibroblastlike cells that, together with other stromal cell populations, participate in the generation of dense collagenous stroma, the 
so called desmoplastic response, typically observed in breast cancer [156].

CAAs functions are mainly mediated by leptin and adiponectin, two functionally opposite members of the adipokine family, that seem to play a pivotal role in cancer progression [157]. Leptin promotes tumor growth, eliciting the activity of several signaling pathways such as insulinlike growth factor-1 (IGF-1) and HER2 and inducing the expression of MMP-2, MMP-9, and VEGF, which finally promote cell migration and metastatic spreading $[158,159]$. Furthermore, leptin exerts a chemoattractant effect on macrophages and monocytes [160] and stimulates them to produce the inflammatory cytokine TNF- $\alpha$ that in turn manifests proangiogenic activity [161]. On the other hand, adiponectin acts as an antiangiogenic and anti-inflammatory factor that is able to repress proliferation and induce apoptosis in breast cancer cells $[147,162]$. Interestingly, some studies have found that caloric restriction can exert an anticancer effect via alterations in systemic IGF-1 and NF- $\kappa$ B levels [163].

Altogether these data suggest that the recently discovered therapeutic potential of adipocytes could open new and promising perspectives in breast cancer treatment. One example of this comes from the preclinical experience gained with adipokine osteopontin (OPN), also called "early $\mathrm{T}$ cell-activation gene 1," a multifunctional component of the extracellular matrix that has been linked to a plethora of autoimmune diseases [164]. OPN has very recently been rediscovered as a diagnostic and prognostic marker in HER2 positive breast cancer [165] and one whose abnormal expression in patients is linked to poor prognosis [166]. It has also been proposed that the autocrine production of OPN by tumor cells may be an important factor that allows invasion and survival to occur [167]. In fact, the interaction between extracellular matrix deposited OPN and cell adhesion molecules, such as $\alpha_{v} \beta_{3}$ integrins which are overexpressed in BALB-neuT tumors [98], increases both the expression of VEGF in ECs, allowing neovascularization, and the activation of connective tissue growth factor and cysteine-rich angiogenic inducer 61(CYR61), which enhances neovascularization and mammary tumor growth in vivo [168].

As previously mentioned, CAAs can differentiate into fibroblast-like cells that share many properties with CAFs [169]. CAFs promote tumor growth and invasion secreting proangiogenic factors (i.e., VEGF-A and MMP-9) [170], proinflammatory molecules (i.e., SDF-1, IL-6, and IL-1 $\beta$ ) [171], and several growth factors (i.e., TGF- $\beta$, platelet-derived growth factor, PDGF, and basic fibroblast growth factor, bFGF) $[172,173]$. In particular, the aberrant production of IL6 and CCL2 in mammary cancer activates STAT3 in CAFs, which finally sustains tumor-associated inflammation and is required for breast cancer cell migration [174]. Certainly, in BALB-neuT mice this network seems to be particularly interesting, as in a BALB-neuT mice knock-in for a constitutively active Stat 3 allele, we observed an earlier and more invasive onset of mammary tumors [175].

\section{MSCs Are Key Players in the TME Orchestra}

Adult multipotent MSCs make for a fascinating TME population which is able to control the interplay between cancer cells and tumor stroma. Physiologically, MSCs are located predominantly in the bone marrow and contribute to the maintenance and regeneration of a variety of connective tissues [176]. During injury and inflammation, they are recruited to damaged sites via the release of soluble molecules and operate in tissue remodeling [177].

MSCs also localize into different types of solid tumors which they first migrate towards then integrate into the tumor-associated stroma [178]. Recent studies have provided direct evidence that MSCs are recruited in TME by a broad range of soluble factors which are secreted by cancer cells and CSCs, including IL-6 [179], VEGF and bFGF [180], CCL2 [181], SDF-1 $\alpha$ [182], and HMGB1 [183]. Moreover, stressful conditions, such as irradiation [184], hypoxia [185] and, cellular damage [183], can enhance the recruitment of MSCs to the site of growing tumors. Once there, MSCs contribute to the development of an active TME, in which bone marrowderived MSCs generate CAFs, while local adipose tissuederived MSCs contribute mainly to the vascular and fibrovascular stroma (pericytes, myofibroblasts, and ECs) [186]. In addition, MSCs interact with tumor cells and with all other stromal cells through a broad range of signaling molecules, generating complex crosstalk whose net effect is to stimulate tumor progression. For example, MSCs can promote breast cancer neoangiogenesis, possibly thorough the secretion of macrophage inflammatory protein 2 (MIP-2), VEGF, TGF$\beta$, and IL-6 [187] and display potent immunomodulatory properties [188] that enable them to inhibit CTLs and NK cells by stimulating Tregs through the release of TGF- $\beta 1$ [189].

Conflicting data have led to the hypothesis that two opposing immunological MSC phenotypes exist, one proinflammatory and one immunosuppressive, which are dependent on the engagement of specific TLRs [190]. The role of TLR2 is still debated, with some studies claiming that TLR2 activation on MSCs inhibits their immunosuppressive properties [191], while others argue that TLR2 stimulation does not affect this capability [192]. Notably, these considerations are mostly based on in vitro experiments. Therefore, BALBneuT mice may well be a suitable tool for the difficult task of definitely clarifying the role of TLR2 in MSCs. Starting from our observation that TLR2 drives mammary CSC selfrenewal [62], we are developing BALB-neuT mice that are KO for TLR2, in which we would like to characterize the role of TLR2 not only in CSCs but also in MSCs and other stromal populations.

MSCs are thought to contribute to CSC niche generation, thus regulating cancer cell stemness through multiple pathways and secreted factors (i.e., IL-6 and CXCL7 [193], PGE-2 [194], EGF, bFGF, bone morphogenic protein (BMP) 4, TGF$\beta 1$, SDF- $1 \alpha$, and CCL5 [195], among others) that increase CSC self-renewal and expand the CSC population.

Furthermore, MSCs promote various malignant features; they control the metastatic ability of breast cancer cells by inducing EMT through the secretion of PDGF-D [196], TGF$\beta 1$ [197], IL-6, and VEGF [198] and promote cancer cell 
migration through the release of a plethora of chemokines such as CCL5 [199], CXCL1 and CXCL5 [200], CXCL9, CXCL10, and CXCL11 [201] or SDF-1 [202]. For all these reasons, MSCs represent an attractive target when considering the design of new and promising anticancer treatments. However, the lack of specific markers that discriminate MSCs from other cell types makes the direct targeting of the MSC population an unrealistic approach. An attempt to disrupt signaling pathways between MSCs and CSCs is more feasible. In fact, the experience we have gained with the BALB-neuT model suggests that some of the molecules released by MSCs, such as IL-6, TGF- $\beta$, and HMGB1, are key molecules in CSC self-renewal and cancer progression [62]. The targeting of these molecules or their receptors, which are somehow redundant in different malignant processes, may be a means by which to interfere with tumor pathogenesis on multiple levels.

In recent years, there has been growing interest in the use of MSCs as a tool for the target-specific delivery of therapeutic agents, because their avid tumor tropism means that they can act as a sort of Trojan horse. MSCs can be genetically engineered to express antitumor cytokines, such as IFN- $\beta$ [203], IL-12 [204], and TRAIL [205], or prodrugs such as cytosine deaminase [206], which are then released directly into the tumor milieu, thus greatly reducing their systemic toxicity. These approaches have been shown to be effective in the management of various preclinical tumor models. However, these killer MSCs may still maintain all the protumoral features here described and some concerns still exist about the potential conversion of MSCs into cancer cells themselves [207]. Therefore, the actual exploitation of MSCs as a tool for anticancer therapy still needs more study, and BALB-neuT mice represent a good model through which to evaluate the feasibility of this approach, in the context of HER2 positive breast cancers.

\section{Conclusions}

The growth and progression of breast cancer cells depend not only on their intrinsic malignant potential but also on a mutual and continuous dialogue between cancer cells and stromal, immune, and endothelial cells within TME. Multidirectional interactions between several substances, such as cytokines, MMPs, and growth factors, secreted by all these populations closely cooperate for the generation of a permissive TME that is crucial for successful cancer progression. This complex and finely tuned interplay between cancer and stromal cells during breast cancer development is summarized in Figure 1.

Experimental studies, conducted on preclinical models, have provided significant hints as to how TME affects tumor progression and response to therapy. BALB-neuT mice are an emblematic example in this regard. Over the years, the exploitation of this model has allowed the identification of novel molecular targets to be carried out and has prompted us to develop new, promising therapeutic approaches. On the other hand, it has provided evidence that the direct targeting of cancer cells is not enough to obtain complete disease remission. This highlights the need to extend antitumor intervention beyond the tumor bulk, as targeting both cancer cells and other TME cell populations may be a more complete and effective strategy.

Given the significant role that CSCs play in the various steps of tumor development and TME modulation, we have recently focused on the identification of pathways that regulate CSC self-renewal and influence, on TME as well as on the investigation of CSC-specific antigens. Another promising field of study can be found in action on tumor angiogenesis; in particular, strategies that modulate vessel permeability may also stabilize tumor vessels and favor both the distribution of traditional drugs into the tumor milieu and immune cell accessibility. As in the BALB-neuT model, the tumor infiltrate is mainly composed of immunosuppressive cells. The addition of immunomodulatory strategies to standard anticancer approaches could be essential for a therapeutic success.

Other TME cell populations, which are still almost unexplored in this model and whose involvement in tumor pathogenesis is still in its infancy, are found in CAAs and CAFs. Given the tissue organization of mammary glands and of the tumor within, which is rich in adipose cells and fibrous tissue, the identification of markers that are overexpressed by CAFs and CAAs may lead to the eradication of these cells which favor cancer progression through the production of various cytokines and extracellular matrix proteins. The blockade of these soluble molecules or their receptors may be an interesting option, as the disruption of the TME signaling network may make cancer cells themselves more amenable to traditional approaches. The drugs used in these combined treatments may be successfully delivered to TME by exploiting the avid tropism of MSCs, which may be engineered in order to produce molecules that inhibit the different populations present into the TME.

In conclusion, the targeting of multiple TME populations may represent the best strategy for setting up innovative anticancer treatments that significantly improve patient survival and shrink the development of drug resistance; in this regard, BALB-neuT mice provide a suitable experimental setting, thanks to the high translational value of this model.

\section{Conflict of Interests}

The authors declare that there is no conflict of interests regarding the publication of this paper.

\section{Authors' Contribution}

Federica Cavallo and Stefania Lanzardo equally contributed to this paper.

\section{Acknowledgments}

This work was supported by Grants from the Italian Association for Cancer Research (IG 11675), Fondazione Ricerca Molinette Onlus, the University of Turin, and the Compagnia di San Paolo (Progetti di Ricerca Ateneo/CSP). This work has 
been supported by Fondazione Veronesi that granted L.C. in the 2014 Pink is Good Program. The authors thank Dr. Dale Lawson for critically reading the paper.

\section{References}

[1] H. Korkaya, S. Liu, and M. S. Wicha, "Breast cancer stem cells, cytokine networks, and the tumor microenvironment," Journal of Clinical Investigation, vol. 121, no. 10, pp. 3804-3809, 2011.

[2] P. Zhou, D. R. Shaffer, D. A. Alvarez Arias et al., "In vivo discovery of immunotherapy targets in the tumour microenvironment," Nature, vol. 506, no. 7486, pp. 52-57, 2014.

[3] F. Cavallo, R. A. Calogero, and G. Forni, "Are oncoantigens suitable targets for anti-tumour therapy?" Nature Reviews Cancer, vol. 7, no. 9, pp. 707-713, 2007.

[4] M. Iezzi, E. Quaglino, A. Amici, P. L. Lollini, G. Forni, and F. Cavallo, "DNA vaccination against oncoantigens: a promise," Oncoimmunology, vol. 1, no. 3, pp. 316-325, 2012.

[5] S. Ménard, P. Casalini, M. Campiglio, S. Pupa, R. Agresti, and E. Tagliabue, "HER2 overexpression in various tumor types, focussing on its relationship to the development of invasive breast cancer," Annals of Oncology, vol. 12, supplement 1, pp. S15-S19, 2001.

[6] D. J. Slamon, G. M. Clark, and S. G. Wong, "Human breast cancer: correlation of relapse and survival with amplification of the HER-2/neu oncogene," Science, vol. 235, no. 4785, pp. 177$182,1987$.

[7] D. L. Nielsen, M. Andersson, and C. Kamby, "HER2-targeted therapy in breast cancer. Monoclonal antibodies and tyrosine kinase inhibitors," Cancer Treatment Reviews, vol. 35, no. 2, pp. 121-136, 2009.

[8] J. C. Thery, J. P. Spano, D. Azria, E. Raymond, and F. Penault Llorca, "Resistance to human epidermal growth factor receptor type 2-targeted therapies," European Journal of Cancer, vol. 50, no. 5, pp. 892-901, 2014.

[9] X.-R. Ren, J. Wei, G. Lei et al., "Polyclonal HER2-specific antibodies induced by vaccination mediate receptor internalization and degradation in tumor cells," Breast Cancer Research, vol. 14, no. 3, p. R89, 2012.

[10] F. M. Frame and N. J. Maitland, "Cancer stem cells, models of study and implications of therapy resistance mechanisms," Advances in Experimental Medicine and Biology, vol. 720, pp. 105-118, 2011.

[11] S. Rovero, A. Amici, E. Di Carlo et al., "DNA vaccination against rat Her-2/Neu p185 more effectively inhibits carcinogenesis than transplantable carcinomas in transgenic BALB/c mice," Journal of Immunology, vol. 165, no. 9, pp. 5133-5142, 2000.

[12] F. Cavallo, R. Offringa, S. H. van der Burg, G. Forni, and C. J. M. Melief, "Vaccination for treatment and prevention of cancer in animal models," Advances in Immunology, vol. 90, pp. 175-213, 2006.

[13] E. Quaglino, S. Rolla, M. Iezzi et al., "Concordant morphologic and gene expression data show that a vaccine halts HER-2/neu preneoplastic lesions," Journal of Clinical Investigation, vol. 113, no. 5, pp. 709-717, 2004.

[14] F. Cavallo, A. Astolfi, M. Iezzi et al., "An integrated approach of immunogenomics and bioinformatics to identify new Tumor Associated Antigens (TAA) for mammary cancer immunological prevention,” BMC Bioinformatics, vol. 6, no. 4, article S7, 2005.
[15] A. M. Scott, J. P. Allison, and J. D. Wolchok, "Monoclonal antibodies in cancer therapy," Cancer Immunity, vol. 12, p. 14, 2012.

[16] G. D. Phillips, C. T. Fields, G. Li et al., "Dual targeting of HER2positive cancer with trastuzumab emtansine and pertuzumab: critical role for neuregulin blockade in antitumor response to combination therapy," Clinical Cancer Research, vol. 20, no. 2, pp. 456-468, 2014.

[17] J. Baselga, J. Cortés, S.-B. Kim et al., "Pertuzumab plus trastuzumab plus docetaxel for metastatic breast cancer," The New England Journal of Medicine, vol. 366, no. 2, pp. 109-119, 2012.

[18] V. Guarneri, E. Barbieri, M. V. Dieci, F. Piacentini, and P. Conte, "Anti-HER2 neoadjuvant and adjuvant therapies in HER2 positive breast cancer," Cancer Treatment Reviews, vol. 36, supplement 3, pp. S62-S66, 2010.

[19] P. L. Lollini, F. Cavallo, C. De Giovanni, and P. Nanni, "Preclinical vaccines against mammary carcinoma," Expert Review of Vaccines, vol. 12, no. 12, pp. 1449-1463, 2013.

[20] E. Quaglino, M. Iezzi, C. Mastini et al., "Electroporated DNA vaccine clears away multifocal mammary carcinomas in her2/neu transgenic mice," Cancer Research, vol. 64, no. 8, pp. 2858-2864, 2004.

[21] A. Porzia, S. Lanzardo, A. Citti et al., "Attenuation of PI3K/Akt-mediated tumorigenic signals through PTEN activation by DNA vaccine-induced anti-ErbB2 antibodies," Journal of Immunology, vol. 184, no. 8, pp. 4170-4177, 2010.

[22] E. Quaglino, C. Mastini, A. Amici et al., "A better immune reaction to Erbb-2 tumors is elicited in mice by DNA vaccines encoding rat/human chimeric proteins," Cancer Research, vol. 70, no. 7, pp. 2604-2612, 2010.

[23] E. Quaglino, F. Riccardo, M. Macagno et al., "Chimeric DNA vaccines against ErbB2+ carcinomas: from mice to humans," Cancers, vol. 3, no. 3, pp. 3225-3241, 2011.

[24] E. Bolli, E. Quaglino, M. Arigoni et al., "Oncoantigens for an immune prevention of cancer," The American Journal of Cancer Research, vol. 1, no. 2, pp. 255-264, 2011.

[25] L. Vera-Ramirez, P. Sanchez-Rovira, C. L. Ramirez-Tortosa et al., "Gene-expression profiles, tumor microenvironment, and cancer stem cells in breast cancer: latest advances towards an integrated approach," Cancer Treatment Reviews, vol. 36, no. 6, pp. 477-484, 2010.

[26] A. Goltsov, D. Faratian, S. P. Langdon, P. Mullen, D. J. Harrison, and J. Bown, "Features of the reversible sensitivity-resistance transition in PI3K/PTEN/AKT signalling network after HER2 inhibition," Cellular Signalling, vol. 24, no. 2, pp. 493-504, 2012.

[27] R. A. Calogero, E. Quaglino, S. Saviozzi, G. Forni, and F. Cavallo, "Oncoantigens as anti-tumor vaccination targets: the chance of a lucky strike?” Cancer Immunology, Immunotherapy, vol. 57, no. 11, pp. 1685-1694, 2008.

[28] Y. Qian, L. Shen, L. Cheng, Z. Wu, and H. Yao, "B7-H4 expression in various tumors determined using a novel developed monoclonal antibody," Clinical and Experimental Medicine, vol. 11, no. 3, pp. 163-170, 2011.

[29] S. Lu, K. Singh, S. Mangray et al., "Claudin expression in highgrade invasive ductal carcinoma of the breast: correlation with the molecular subtype," Modern Pathology, vol. 26, no. 4, pp. 485-495, 2013.

[30] P. Xing, J.-G. Li, F. Jin et al., "Clinical and biological significance of hepsin overexpression in breast cancer," Journal of Investigative Medicine, vol. 59, no. 5, pp. 803-810, 2011. 
[31] B. Bisig, P. Gaulard, and L. De Leval, "New biomarkers in T-cell lymphomas," Best Practice and Research: Clinical Haematology, vol. 25, no. 1, pp. 13-28, 2012.

[32] W. K. Fang, W. Gu, L. D. Liao et al., "Prognostic significance of desmoglein 2 and desmoglein 3 in esophageal squamous cell carcinoma," Asian Pacific Journal of Cancer Prevention, vol. 15, no. 2, pp. 871-876, 2014.

[33] K. K. Haagenson and G. S. Wu, "Mitogen activated protein kinase phosphatases and cancer," Cancer Biology and Therapy, vol. 9, no. 5, pp. 337-340, 2010.

[34] L. Klampfer, "The role of signal transducers and activators of transcription in colon cancer," Frontiers in Bioscience, vol. 13, no. 8, pp. 2888-2899, 2008.

[35] G. Vader and S. M. A. Lens, "The Aurora kinase family in cell division and cancer," Biochimica et Biophysica Acta, vol. 1786, no. 1, pp. 60-72, 2008.

[36] E. L. Mayer and I. E. Krop, "Advances in targeting Src in the treatment of breast cancer and other solid malignancies," Clinical Cancer Research, vol. 16, no. 14, pp. 3526-3532, 2010.

[37] B. N. Rexer and C. L. Arteaga, "Optimal targeting of HER2-PI3K signaling in breast cancer: mechanistic insights and clinical implications," Cancer Research, vol. 73, no. 13, pp. 3817-3820, 2013.

[38] N. Shafee, C. R. Smith, S. Wei et al., "Cancer stem cells contribute to cisplatin resistance in Brcal/p53-mediated mouse mammary tumors," Cancer Research, vol. 68, no. 9, pp. 32433250, 2008.

[39] I. Beyer, H. Cao, J. Persson et al., "Coadministration of epithelial junction opener JO-1 improves the efficacy and safety of chemotherapeutic drugs," Clinical Cancer Research, vol. 18, no. 12, pp. 3340-3351, 2012.

[40] H. Zhou, Y. Zhang, Y. Fu, L. Chan, and A. S. Lee, "Novel mechanism of anti-apoptotic function of $78-\mathrm{kDa}$ glucoseregulated protein (GRP78): endocrine resistance factor in breast cancer, through release of B-cell lymphoma 2 (BCL-2) from BCL-2-interacting killer (BIK)," Journal of Biological Chemistry, vol. 286, no. 29, pp. 25687-25696, 2011.

[41] K. N. Shah, K. R. Mehta, D. Peterson, M. Evangelista, J. C. Livesey, and J. S. Faridi, "AKT-induced tamoxifen resistance is overturned by RRM2 inhibition," Molecular Cancer Research, vol. 12, no. 3, pp. 394-407, 2014.

[42] L. W. Hebbard, J. Maurer, A. Miller et al., "Maternal embryonic leucine zipper kinase is upregulated and required in mammary tumor-initiating cells in vivo," Cancer Research, vol. 70, no. 21, pp. 8863-8873, 2010.

[43] T.-H. Hsieh, C.-F. Tsai, C.-Y. Hsu et al., "Phthalates stimulate the epithelial to mesenchymal transitionthrough an HDAC6dependent mechanism in human breastepithelial stem cells," Toxicological Sciences, vol. 128, no. 2, pp. 365-376, 2012.

[44] J. Regan, T. Sourisseau, K. Soady et al., "Aurora A kinase regulates mammary epithelial cell fate by determining mitotic spindle orientation in a Notch-dependent manner," Cell Reports, vol. 4, no. 1, pp. 110-123, 2013.

[45] V. S. Nair, L. S. Maeda, and J. P. A. Ioannidis, "Clinical outcome prediction by MicroRNAs in human cancer: a systematic review," Journal of the National Cancer Institute, vol. 104, no. 7, pp. 528-540, 2012.

[46] S. F. Tavazoie, C. Alarcón, T. Oskarsson et al., "Endogenous human microRNAs that suppress breast cancer metastasis," Nature, vol. 451, no. 7175, pp. 147-152, 2008.
[47] C. Urbich, A. Kuehbacher, and S. Dimmeler, "Role of microRNAs in vascular diseases, inflammation, and angiogenesis," Cardiovascular Research, vol. 79, no. 4, pp. 581-588, 2008.

[48] J. A. Wright, J. K. Richer, and G. J. Goodall, "MicroRNAs and EMT in mammary cells and breast cancer," Journal of Mammary Gland Biology and Neoplasia, vol. 15, no. 2, pp. 213-223, 2010.

[49] M. Arigoni, G. Barutello, F. Riccardo et al., "MiR-135b coordinates progression of ErbB2-driven mammary carcinomas through suppression of MID1 and MTCH2," The American Journal of Pathology, vol. 182, no. 6, pp. 2058-2070, 2013.

[50] Y. X. Wang, X. Y. Zhang, B. F. Zhang, C. Q. Yang, X. M. Chen, and H. J. Gao, "Initial study of microRNA expression profiles of colonic cancer without lymph node metastasis," Journal of Digestive Diseases, vol. 11, no. 1, pp. 50-54, 2010.

[51] R. R. Lulla, F. F. Costa, J. M. Bischof et al., "Identification of differentially expressed microRNAs in osteosarcoma," Sarcoma, vol. 2011, Article ID 732690, 6 pages, 2011.

[52] F. F. Costa, J. M. Bischof, E. F. Vanin et al., "Identification of micrornas as potential prognostic markers in ependymoma," PLoS ONE, vol. 6, no. 10, Article ID e25114, 2011.

[53] S. Liu, W. Guo, J. Shi et al., "MicroRNA-135a contributes to the development of portal vein tumor thrombus by promoting metastasis in hepatocellular carcinoma," Journal of Hepatology, vol. 56, no. 2, pp. 389-396, 2012.

[54] N. Y. Frank, T. Schatton, and M. H. Frank, "The therapeutic promise of the cancer stem cell concept," Journal of Clinical Investigation, vol. 120, no. 1, pp. 41-50, 2010.

[55] L. V. Nguyen, R. Vanner, P. Dirks, and C. J. Eaves, "Cancer stem cells: an evolving concept," Nature Reviews Cancer, vol. 12, no. 2, pp. 133-143, 2012.

[56] F. Cordero, M. Beccuti, C. Fornari et al., "Multi-level model for the investigation of oncoantigen-driven vaccination effect," BMC Bioinformatics, vol. 14, supplement 6, p. S11, 2013.

[57] E. Fessler, F. E. Dijkgraaf, F. De Sousa E Melo, and J. P. Medema, "Cancer stem cell dynamics in tumor progression and metastasis: is the microenvironment to blame?" Cancer Letters, vol. 341, no. 1, pp. 97-104, 2013.

[58] A. R. Chin and S. E. Wang, "Cytokines driving breast cancer stemness," Molecular and Cellular Endocrinology, vol. 382, no. 1, pp. 598-602, 2014.

[59] Z. C. Hartman, X.-Y. Yang, O. Glass et al., "HER2 overexpression elicits a proinflammatory IL-6 autocrine signaling loop that is critical for tumorigenesis," Cancer Research, vol. 71, no. 13, pp. 4380-4391, 2011.

[60] H. Korkaya, G.-I. Kim, A. Davis et al., "Activation of an IL6 inflammatory loop mediates trastuzumab resistance in HER2 ${ }^{+}$ breast cancer by expanding the cancer stem cell population," Molecular Cell, vol. 47, no. 4, pp. 570-584, 2012.

[61] C. Grange, S. Lanzardo, F. Cavallo, G. Camussi, and B. Bussolati, "SCA-1 identifies the tumor-initiating cells in mammary tumors of BALB-neuT trangenic mice," Neoplasia, vol. 10, no. 12, pp. 1433-1443, 2008.

[62] L. Conti, S. Lanzardo, M. Arigoni et al., “The noninflammatory role of high mobility group box 1/Toll-like receptor 2 axis in the self-renewal of mammary cancer stem cells," The FASEB Journal, vol. 27, no. 12, pp. 4731-4744, 2013.

[63] M. Pickup, S. Novitskiy, and H. L. Moses, "The roles of TGFbeta in the tumour microenvironment," Nature Reviews Cancer, vol. 13, no. 11, pp. 788-799, 2013.

[64] A. Chiechi, D. L. Waning, K. R. Stayrook, J. T. Buijs, T. A. Guise, and K. S. Mohammad, "Role of TGF- in breast cancer bone 
metastases," Advances in Bioscience and Biotechnology, vol. 4, no. 10C, pp. 15-30, 2013.

[65] M. E. Bianchi and A. A. Manfredi, "High-mobility group box 1 (HMGB1) protein at the crossroads between innate and adaptive immunity," Immunological Reviews, vol. 220, no. 1, pp. 35-46, 2007.

[66] P. Scaffidi, T. Misteli, and M. E. Bianchi, "Release of chromatin protein HMGB1 by necrotic cells triggers inflammation," Nature, vol. 418, no. 6894, pp. 191-195, 2002.

[67] J. Singh, B. M. Simões, S. J. Howell, G. Farnie, and R. B. Clarke, "Recent advances reveal IL-8 signalling as a potential key to targeting breast cancer stem cells," Breast Cancer Research, vol. 15, no. 4, p. 210, 2013.

[68] J. K. Singh, G. Farnie, N. J. Bundred et al., "Targeting CXCR1/2 significantly reduces breast cancer stem cell activity and increases the efficacy of inhibiting HER2 via HER2-dependent and -independent mechanisms," Clinical Cancer Research, vol. 19, no. 3, pp. 643-656, 2013.

[69] C. Ginestier, S. Liu, M. E. Diebel et al., "CXCR1 blockade selectively targets human breast cancer stem cells in vitro and in xenografts," Journal of Clinical Investigation, vol. 120, no. 2, pp. 485-497, 2010.

[70] A. Tsuyada, A. Chow, J. Wu et al., "CCL2 mediates crosstalk between cancer cells and stromal fibroblasts that regulates breast cancer stem cells," Cancer Research, vol. 72, no. 11, pp. 2768-2779, 2012.

[71] R. A. Calogero, F. Cordero, G. Forni, and F. Cavallo, "Inflammation and breast cancer. Inflammatory component of mammary carcinogenesis in ErbB2 transgenic mice," Breast Cancer Research, vol. 9, no. 4, article 211, 2007.

[72] I. Conti and B. J. Rollins, "CCL2 (monocyte chemoattractant protein-1) and cancer," Seminars in Cancer Biology, vol. 14, no. 3, pp. 149-154, 2004.

[73] I. H. Benoy, R. Salgado, P. Van Dam et al., "Increased serum interleukin- 8 in patients with early and metastatic breast cancer correlates with early dissemination and survival," Clinical Cancer Research, vol. 10, no. 21, pp. 7157-7162, 2004.

[74] O. I. Ahmed, A. M. Adel, D. R. Diab, and N. S. Gobran, "Prognostic value of serum level of interleukin-6 and interleukin-8 in metastatic breast cancer patients," The Egyptian Journal of Immunology, vol. 13, no. 2, pp. 61-68, 2006.

[75] C.-Y. Li, S. Shan, Q. Huang et al., "Initial stages of tumor cellinduced angiogenesis: evaluation via skin window chambers in rodent models," Journal of the National Cancer Institute, vol. 92, no. 2, pp. 143-147, 2000.

[76] D. J. Hicklin and L. M. Ellis, "Role of the vascular endothelial growth factor pathway in tumor growth and angiogenesis," Journal of Clinical Oncology, vol. 23, no. 5, pp. 1011-1027, 2005.

[77] K. J. Kim, B. Li, J. Winer et al., "Inhibition of vascular endothelial growth factor-induced angiogenesis suppresses tumour growth in vivo," Nature, vol. 362, no. 6423, pp. 841-844, 1993.

[78] A. Grothey and L. M. Ellis, "Targeting angiogenesis driven by vascular endothelial growth factors using antibody-based therapies," Cancer Journal, vol. 14, no. 3, pp. 170-177, 2008.

[79] D. B. Mendel, A. Douglas Laird, X. Xin et al., "In vivo antitumor activity of SU11248, a novel tyrosine kinase inhibitor targeting vascular endothelial growth factor and plateletderived growth factor receptors: determination of a pharmacokinetic/pharmacodynamic relationship," Clinical Cancer Research, vol. 9, no. 1 I, pp. 327-337, 2003.
[80] L. Adnane, P. A. Trail, I. Taylor, and S. M. Wilhelm, "Sorafenib (BAY 43-9006, Nexavar), a dual-action inhibitor that targets $\mathrm{RAF} / \mathrm{MEK} / \mathrm{ERK}$ pathway in tumor cells and tyrosine kinases VEGFR/PDGFR in tumor vasculature," Methods in Enzymology, vol. 407, pp. 597-612, 2005.

[81] L. J. Wilmes, M. G. Pallavicini, L. M. Fleming et al., "AG-013736, a novel inhibitor of VEGF receptor tyrosine kinases, inhibits breast cancer growth and decreases vascular permeability as detected by dynamic contrast-enhanced magnetic resonance imaging," Magnetic Resonance Imaging, vol. 25, no. 3, pp. 319327, 2007.

[82] G. Sonpavde and T. E. Hutson, "Pazopanib: a novel multitargeted tyrosine kinase inhibitor," Current Oncology Reports, vol. 9, no. 2, pp. 115-119, 2007.

[83] A. J. Ryan and S. R. Wedge, "ZD6474-a novel inhibitor of VEGFR and EGFR tyrosine kinase activity," British Journal of Cancer, vol. 92, supplement 1, pp. S6-S13, 2005.

[84] U. Vaishampayan, "Cabozantinib as a novel therapy for renal cell carcinoma," Current Oncology Reports, vol. 15, no. 2, pp. 7682, 2013.

[85] D. A. Nosov, B. Esteves, O. N. Lipatov et al., "Antitumor activity and safety of tivozanib (AV-951) in a phase II randomized discontinuation trial in patients with renal cell carcinoma," Journal of Clinical Oncology, vol. 30, no. 14, pp. 1678-1685, 2012.

[86] D. H. Albert, P. Tapang, T. J. Magoc et al., "Preclinical activity of ABT-869, a multitargeted receptor tyrosine kinase inhibitor," Molecular Cancer Therapeutics, vol. 5, no. 4, pp. 995-1006, 2006.

[87] S. Giuliano and G. Pagès, "Mechanisms of resistance to antiangiogenesis therapies," Biochimie, vol. 95, no. 6, pp. 1110-1119, 2013.

[88] M. Ernkvist, O. Birot, I. Sinha et al., "Differential roles of p80and p130-angiomotin in the switch between migration and stabilization of endothelial cells," Biochimica et Biophysica Acta, vol. 1783, no. 3, pp. 429-437, 2008.

[89] B. Troyanovsky, T. Levchenko, G. Månsson, O. Matvijenko, and L. Holmgren, "Angiomotin: an angiostatin binding protein that regulates endothelial cell migration and tube formation," Journal of Cell Biology, vol. 152, no. 6, pp. 1247-1254, 2001.

[90] A. Bratt, W. J. Wilson, B. Troyanovsky et al., "Angiomotin belongs to a novel protein family with conserved coiled-coil and PDZ binding domains," Gene, vol. 298, no. 1, pp. 69-77, 2002.

[91] W. G. Jiang, G. Watkins, A. Douglas-Jones, L. Holmgren, and R. E. Mansel, "Angiomotin and angiomotin like proteins, their expression and correlation with angiogenesis and clinical outcome in human breast cancer," BMC cancer, vol. 6, article 16, 2006.

[92] E. Y. Lin, J. G. Jones, P. Li et al., "Progression to malignancy in the polyoma middle $\mathrm{T}$ oncoprotein mouse breast cancer model provides a reliable model for human diseases," The American Journal of Pathology, vol. 163, no. 5, pp. 2113-2126, 2003.

[93] M. Arigoni, G. Barutello, S. Lanzardo et al., "A vaccine targeting angiomotin induces an antibody response which alters tumor vessel permeability and hampers the growth of established tumors," Angiogenesis, vol. 15, no. 2, pp. 305-316, 2012.

[94] Y. Zheng, S. Vertuani, S. Nyström et al., "Angiomotin-like protein 1 controls endothelial polarity and junction stability during sprouting angiogenesis," Circulation Research, vol. 105, no. 3, pp. 260-270, 2009.

[95] Q. Li, G. Kondoh, S. Inafuku, Y. Nishimune, and A. Hakura, "Abrogation of c-kit/Steel factor-dependent tumorigenesis by kinase defective mutants of the c-kit receptor: c-kit Kinase 
defective mutants as candidate tools for cancer gene therapy," Cancer Research, vol. 56, no. 19, pp. 4343-4346, 1996.

[96] J. L. Regan, H. Kendrick, F.-A. Magnay, V. Vafaizadeh, B. Groner, and M. J. Smalley, "C-Kit is required for growth and survival of the cells of origin of Brcal-mutation-associated breast cancer," Oncogene, vol. 31, no. 7, pp. 869-883, 2012.

[97] C. Olgasi, P. Dentelli, A. Rosso et al., "DNA vaccination against membrane-bound Kit ligand: a new approach to inhibiting tumour growth and angiogenesis," European Journal of Cancer, vol. 50, no. 1, pp. 234-246, 2014.

[98] L. Conti, S. Lanzardo, M. Iezzi et al., "Optical imaging detection of microscopic mammary cancer in ErbB-2 transgenic mice through the DA364 probe binding $\alpha \mathrm{v} \beta 3$ integrins," Contrast Media and Molecular Imaging, vol. 8, no. 4, pp. 350-360, 2013.

[99] P. C. Brooks, R. A. F. Clark, and D. A. Cheresh, "Requirement of vascular integrin $\alpha \mathrm{v} \beta 3$ for angiogenesis," Science, vol. 264, no. 5158, pp. 569-571, 1994.

[100] E. Ambrosino, M. Spadaro, M. Iezzi et al., "Immunosurveillance of Erbb2 carcinogenesis in transgenic mice is concealed by a dominant regulatory T-cell self-tolerance," Cancer Research, vol. 66, no. 15, pp. 7734-7740, 2006.

[101] J. M. Park, M. Terabe, D. D. Donaldson, G. Forni, and J. A. Berzofsky, "Natural immunosurveillance against spontaneous, autochthonous breast cancers revealed and enhanced by blockade of IL-13-mediated negative regulation," Cancer Immunology, Immunotherapy, vol. 57, no. 6, pp. 907-912, 2008.

[102] S. Bandini, C. Curcio, M. Macagno et al., "Early onset and enhanced growth of autochthonous mammary carcinomas in C3-deficient Her2/neu transgenic mice," Oncoimmunology, vol. 2, no. 9, Article ID e26137, 2013.

[103] S. E. A. Street, N. Zerafa, M. Iezzi et al., "Host perforin reduces tumor number but does not increase survival in oncogenedriven mammary adenocarcinoma," Cancer Research, vol. 67, no. 11, pp. 5454-5460, 2007.

[104] F. Cavallo, C. De Giovanni, P. Nanni, G. Forni, and P.-L. Lollini, "2011: the immune hallmarks of cancer," Cancer Immunology, Immunotherapy, vol. 60, no. 3, pp. 319-326, 2011.

[105] M. Coscia, E. Quaglino, M. Iezzi et al., “Zoledronic acid repolarizes tumour-associated macrophages and inhibits mammary carcinogenesis by targeting the mevalonate pathway," Journal of Cellular and Molecular Medicine, vol. 14, no. 12, pp. 2803-2815, 2010.

[106] C. Mastini, P. D. Becker, M. Iezzi et al., "Intramammary application of non-methylated-CpG oligodeoxynucleotides ( $\mathrm{CpG}$ ) inhibits both local and systemic mammary carcinogenesis in female BALB/c Her-2/neu transgenic mice," Current Cancer Drug Targets, vol. 8, no. 3, pp. 230-242, 2008.

[107] A. Sica, T. Schioppa, A. Mantovani, and P. Allavena, "Tumourassociated macrophages are a distinct M2 polarised population promoting tumour progression: potential targets of anti-cancer therapy," European Journal of Cancer, vol. 42, no. 6, pp. 717-727, 2006.

[108] M. Spadaro, E. Ambrosino, M. Iezzi et al., "Cure of mammary carcinomas in Her-2 transgenic mice through sequential stimulation of innate (neoadjuvant interleukin-12) and adaptive (DNA vaccine electroporation) immunity," Clinical Cancer Research, vol. 11, no. 5, pp. 1941-1952, 2005.

[109] L. Cifaldi, E. Quaglino, E. Di Carlo et al., "A light, nontoxic interleukin 12 protocol inhibits HER-2/neu mammary carcinogenesis in $\mathrm{BALB} / \mathrm{c}$ transgenic mice with established hyperplasia," Cancer Research, vol. 61, no. 7, pp. 2809-2812, 2001.
[110] M. Vagliani, M. Rodolfo, F. Cavallo et al., "Interleukin 12 potentiates the curative effect of a vaccine based on interleukin 2-transduced tumor cells," Cancer Research, vol. 56, no. 3, pp. 467-470, 1996.

[111] R. J. Moore, D. M. Owens, G. Stamp et al., "Mice deficient in tumor necrosis factor-alpha are resistant to skin carcinogenesis," Nature Medicine, vol. 5, no. 7, pp. 828-831, 1999.

[112] X. Song, Y. Krelin, T. Dvorkin et al., "CD11b+/Gr-1+ immature myeloid cells mediate suppression of $\mathrm{T}$ cells in mice bearing tumors of IL- $1 \beta$-secreting cells," Journal of Immunolog $y$, vol. 175, no. 12, pp. 8200-8208, 2005.

[113] C. Melani, C. Chiodoni, G. Forni, and M. P. Colombo, "Myeloid cell expansion elicited by the progression of spontaneous mammary carcinomas in c-erbB-2 transgenic BALB/c mice suppresses immune reactivity," Blood, vol. 102, no. 6, pp. 21382145, 2003.

[114] J. Bromberg, "Stat proteins and oncogenesis," Journal of Clinical Investigation, vol. 109, no. 9, pp. 1139-1142, 2002.

[115] B. Almand, J. I. Clark, E. Nikitina et al., "Increased production of immature myeloid cells in cancer patients: a mechanism of immunosuppression in cancer," Journal of Immunology, vol. 166, no. 1, pp. 678-689, 2001.

[116] C. Melani, S. Sangaletti, F. M. Barazzetta, Z. Werb, and M. P. Colombo, "Amino-biphosphonate-mediated MMP-9 inhibition breaks the tumor-bone marrow axis responsible for myeloidderived suppressor cell expansion and macrophage infiltration in tumor stroma," Cancer Research, vol. 67, no. 23, pp. 1143811446, 2007.

[117] B. Heissig, K. Hattori, S. Dias et al., "Recruitment of stem and progenitor cells from the bone marrow niche requires MMP-9 mediated release of Kit-ligand," Cell, vol. 109, no. 5, pp. 625-637, 2002.

[118] I. Dimova, G. Popivanov, and V. Djonov, "Angiogenesis in cancer-general pathways and their therapeutic implications," Journal of BUON, vol. 19, no. 1, pp. 15-21, 2014.

[119] S. Kusmartsev, E. Eruslanov, H. Kübler et al., "Oxidative stress regulates expression of VEGFR1 in myeloid cells: link to tumorinduced immune suppression in renal cell carcinoma," Journal of Immunology, vol. 181, no. 1, pp. 346-353, 2008.

[120] B. Hoechst, T. Voigtlaender, L. Ormandy et al., "Myeloid derived suppressor cells inhibit natural killer cells in patients with hepatocellular carcinoma via the NKp30 receptor," Hepatology, vol. 50, no. 3, pp. 799-807, 2009.

[121] J. Yu, W. Du, F. Yan et al., "Myeloid-derived suppressor cells suppress antitumor immune responses through IDO expression and correlate with lymph node metastasis in patients with breast cancer," Journal of Immunology, vol. 190, no. 7, pp. 3783-3797, 2013.

[122] N. Obermajer, J. L. Wong, R. P. Edwards, K. Odunsi, K. Moysich, and P. Kalinski, "PGE2-driven induction and maintenance of cancer-associated myeloid-derived suppressor cells," Immunological Investigations, vol. 41, no. 6-7, pp. 635-657, 2012.

[123] Y.-R. Na, Y.-N. Yoon, D.-I. Son, and S.-H. Seok, "Cyclooxygenase-2 inhibition blocks M2 macrophage differentiation and suppresses metastasis in murine breast cancer model," PLoS ONE, vol. 8, no. 5, Article ID e63451, 2013.

[124] B. N. P. Kumar, S. Rajput, K. K. Dey et al., "Celecoxib alleviates tamoxifen-instigated angiogenic effects by ROS-dependent VEGF/VEGFR2 autocrine signaling," BMC Cancer, vol. 13, article 273, 2013. 
[125] M.-C. Yen, C.-C. Lin, Y.-L. Chen et al., "A novel cancer therapy by skin delivery of indoleamine 2,3-dioxygenase siRNA," Clinical Cancer Research, vol. 15, no. 2, pp. 641-649, 2009.

[126] C. He, H. Qiao, H. Jiang, and X. Sun, "The inhibitory role of b7h4 in antitumor immunity: association with cancer progression and survival," Clinical and Developmental Immunology, vol. 2011, Article ID 695834, 8 pages, 2011.

[127] G. J. Freeman, A. J. Long, Y. Iwai et al., "Engagement of the PD-1 immunoinhibitory receptor by a novel B7 family member leads to negative regulation of lymphocyte activation," Journal of Experimental Medicine, vol. 192, no. 7, pp. 1027-1034, 2000.

[128] J.-I. Youn, S. Nagaraj, M. Collazo, and D. I. Gabrilovich, "Subsets of myeloid-derived suppressor cells in tumor-bearing mice," Journal of Immunology, vol. 181, no. 8, pp. 5791-5802, 2008.

[129] E. Quaglino, C. Mastini, M. Iezzi et al., "The adjuvant activity of BAT antibody enables DNA vaccination to inhibit the progression of established autochthonous Her-2/neu carcinomas in BALB/c mice," Vaccine, vol. 23, no. 25, pp. 3280-3287, 2005.

[130] S. K. Bunt, V. K. Clements, E. M. Hanson, P. Sinha, and S. Ostrand-Rosenberg, "Inflammation enhances myeloid-derived suppressor cell cross-talk by signaling through Toll-like receptor 4," Journal of Leukocyte Biology, vol. 85, no. 6, pp. 996-1004, 2009.

[131] X. Tang, "Tumor-associated macrophages as potential diagnostic and prognostic biomarkers in breast cancer," Cancer Letters, vol. 332, no. 1, pp. 3-10, 2013.

[132] S. Rolla, C. Nicoló, S. Malinarich et al., "Distinct and nonoverlapping $\mathrm{T}$ cell receptor repertoires expanded by DNA vaccination in wild-type and HER-2 transgenic BALB/c mice," Journal of Immunology, vol. 177, no. 11, pp. 7626-7633, 2006.

[133] H. Von Boehmer, "Mechanisms of suppression by suppressor T cells," Nature Immunology, vol. 6, no. 4, pp. 338-344, 2005.

[134] S. Occhipinti, L. Sponton, S. Rolla et al., "Chimeric Rat/Human HER2 efficiently circumvents HER2 tolerance in cancer patients," Clinical Cancer Research, 2014.

[135] M. G. Strainic, J. Liu, D. Huang et al., "Locally produced complement fragments C5a and C3a provide both costimulatory and survival signals to naive CD4+ T cells," Immunity, vol. 28, no. 3, pp. 425-435, 2008.

[136] M. G. Strainic, E. M. Shevach, F. An, F. Lin, and M. E. Medof, "Absence of signaling into $\mathrm{CD}^{+}$cells via $\mathrm{C} 3 \mathrm{aR}$ and C5aR enables autoinductive TGF- $\beta 1$ signaling and induction of Foxp $3^{+}$regulatory T cells," Nature Immunology, vol. 14, no. 2, pp. 162-171, 2013.

[137] W.-H. Kwan, W. van der Touw, E. Paz-Artal, M. O. Li, and P. S. Heeger, "Signaling through C5a receptor and C3a receptor diminishes function of murine natural regulatory $\mathrm{T}$ cells," Journal of Experimental Medicine, vol. 210, no. 2, pp. 257-268, 2013.

[138] P. L. Lollini, G. Nicoletti, L. Landuzzi et al., "Down regulation of major histocompatibility complex class I expression in mammary carcinoma of HER-2/neu transgenic mice," International Journal of Cancer, vol. 77, no. 6, pp. 937-941, 1998.

[139] F. Garrido and I. Algarra, "MHC antigens and tumor escape from immune surveillance," Advances in Cancer Research, vol. 83, pp. 117-158, 2001.

[140] M. Inoue, K. Mimura, S. Izawa et al., "Expression of MHC Class I on breast cancer cells correlates inversely with HER2 expression," Oncoimmunology, vol. 1, no. 7, pp. 1104-1110, 2012.

[141] M. Macagno, S. Bandini, L. Stramucci et al., "Multiple roles of perforin in hampering ERBB-2 (Her-2/neu) carcinogenesis in transgenic male mice," Journal of Immunology, vol. 192, no. 11, pp. 5434-5441, 2014.

[142] R. Tallerico, M. Todaro, S. Di Franco et al., "Human NK cells selective targeting of colon cancer-initiating cells: a role for natural cytotoxicity receptors and MHC class i molecules," Journal of Immunology, vol. 190, no. 5, pp. 2381-2390, 2013.

[143] P. E. Scherer, "Adipose tissue: from lipid storage compartment to endocrine organ," Diabetes, vol. 55, no. 6, pp. 1537-1545, 2006.

[144] A. R. Johnson, J. Justin Milner, and L. Makowski, “The inflammation highway: metabolism accelerates inflammatory traffic in obesity," Immunological Reviews, vol. 249, no. 1, pp. 218-238, 2012.

[145] R. C. Hovey and L. Aimo, "Diverse and active roles for adipocytes during mammary gland growth and function," Journal of Mammary Gland Biology and Neoplasia, vol. 15, no. 3, pp. 279-290, 2010.

[146] Y. Mao, E. T. Keller, D. H. Garfield, K. Shen, and J. Wang, "Stromal cells in tumor microenvironment and breast cancer," Cancer and Metastasis Reviews, vol. 32, no. 1-2, pp. 303-315, 2013.

[147] J. Park, D. M. Euhus, and P. E. Scherer, "Paracrine and endocrine effects of adipose tissue on cancer development and progression," Endocrine Reviews, vol. 32, no. 4, pp. 550-570, 2011.

[148] B. Majed, T. Moreau, K. Senouci, R. J. Salmon, A. Fourquet, and B. Asselain, "Is obesity an independent prognosis factor in woman breast cancer?" Breast Cancer Research and Treatment, vol. 111, no. 2, pp. 329-342, 2008.

[149] J. Ligibel, “Obesity and breast cancer," Oncology, vol. 25, no. 11, pp. 994-1000, 2011.

[150] B. Dirat, L. Bochet, M. Dabek et al., "Cancer-associated adipocytes exhibit an activated phenotype and contribute to breast cancer invasion," Cancer Research, vol. 71, no. 7, pp. 24552465, 2011.

[151] K. Sun, C. M. Kusminski, and P. E. Scherer, "Adipose tissue remodeling and obesity," Journal of Clinical Investigation, vol. 121, no. 6, pp. 2094-2101, 2011.

[152] B. E. Elliott, S.-P. Tam, D. Dexter, and Z. Q. Chen, "Capacity of adipose tissue to promote growth and metastasis of a murine mammary carcinoma: effect of estrogen and progesterone," International Journal of Cancer, vol. 51, no. 3, pp. 416-424, 1992.

[153] J. M. Fleming, T. C. Miller, M. J. Meyer, E. Ginsburg, and B. K. Vonderhaar, "Local regulation of human breast xenograft models," Journal of Cellular Physiology, vol. 224, no. 3, pp. 795806, 2010.

[154] J. Yamaguchi, H. Ohtani, K. Nakamura, I. Shimokawa, and T. Kanematsu, "Prognostic impact of marginal adipose tissue invasion in ductal carcinoma of the breast," The American Journal of Clinical Pathology, vol. 130, no. 3, pp. 382-388, 2008.

[155] L. M. Berstein, A. Y. Kovalevskij, T. E. Poroshina et al., "Signs of proinflammatory/genotoxic switch (adipogenotoxicosis) in mammary fat of breast cancer patients: role of menopausal status, estrogens and hyperglycemia," International Journal of Cancer, vol. 121, no. 3, pp. 514-519, 2007.

[156] L. Bochet, C. Lehuede, S. Dauvillier et al., "Adipocyte-derived fibroblasts promote tumor progression and contribute to the desmoplastic reaction in breast cancer," Cancer Research, vol. 73, no. 18, pp. 5657-5668, 2013.

[157] M. N. VanSaun, "Molecular pathways: adiponectin and leptin signaling in cancer," Clinical Cancer Research, vol. 19, no. 8, pp. 1926-1932, 2013.

[158] N. K. Saxena, L. Taliaferro-Smith, B. B. Knight et al., "Bidirectional crosstalk between leptin and insulin-like growth factor-I 
signaling promotes invasion and migration of breast cancer cells via transactivation of epidermal growth factor receptor," Cancer Research, vol. 68, no. 23, pp. 9712-9722, 2008.

[159] A. Eisenberg, E. Biener, M. Charlier et al., "Transactivation of erbB2 by short and long isoforms of leptin receptors," FEBS Letters, vol. 565, no. 1-3, pp. 139-142, 2004.

[160] M. L. Gruen, M. Hao, D. W. Piston, and A. H. Hasty, "Leptin requires canonical migratory signaling pathways for induction of monocyte and macrophage chemotaxis," The American Journal of Physiology-Cell Physiology, vol. 293, no. 5, pp. C1481C1488, 2007.

[161] J.-P. Bastard, M. Maachi, C. Lagathu et al., "Recent advances in the relationship between obesity, inflammation, and insulin resistance," European Cytokine Network, vol. 17, no. 1, pp. 4-12, 2006.

[162] T. Jardé, S. Perrier, M.-P. Vasson, and F. Caldefie-Chézet, "Molecular mechanisms of leptin and adiponectin in breast cancer," European Journal of Cancer, vol. 47, no. 1, pp. 33-43, 2011.

[163] A. E. Harvey, L. M. Lashinger, G. Otto, N. P. Nunez, and S. D. Hursting, "Decreased systemic IGF-1 in response to calorie restriction modulates murine tumor cell growth, nuclear factor- $\kappa \mathrm{B}$ activation, and inflammation-related gene expression," Molecular Carcinogenesis, vol. 52, no. 12, pp. 997-1006, 2013.

[164] D. Chabas, S. E. Baranzini, D. Mitchell et al., "The influence of the proinflammatory cytokine, osteopontin, on autoimmue demyelinating desease," Science, vol. 294, no. 5547, pp. 1731-1735, 2001.

[165] M. Mirza, E. Shaughnessy, J. K. Hurley et al., "Osteopontin-c is a selective marker of breast cancer," International Journal of Cancer, vol. 122, no. 4, pp. 889-897, 2008.

[166] D. Thorat, A. Sahu, R. Behera et al., "Association of osteopontin and cyclooxygenase-2 expression with breast cancer subtypes and their use as potential biomarkers," Oncology Letters, vol. 6, no. 6, pp. 1559-1564, 2013.

[167] S. Meierjohann, M. Schartl, and J.-N. Volff, "Genetic, biochemical and evolutionary facets of Xmrk-induced melanoma formation in the fish Xiphophorus," Comparative Biochemistry and Physiology C: Toxicology and Pharmacology, vol. 138, no. 3, pp. 281-289, 2004.

[168] A. C. Cook, A. B. Tuck, S. McCarthy et al., "Osteopontin induces multiple changes in gene expression that reflect the six "hallmarks of cancer" in a model of breast cancer progression," Molecular Carcinogenesis, vol. 43, no. 4, pp. 225-236, 2005.

[169] Y.-Y. Wang, C. Lehuédé, V. Laurent et al., “Adipose tissue and breast epithelial cells: a dangerous dynamic duo in breast cancer," Cancer Letters, vol. 324, no. 2, pp. 142-151, 2012.

[170] C. H. Stuelten, S. DaCosta Byfield, P. R. Arany, T. S. Karpova, W. G. Stetler-Stevenson, and A. B. Roberts, "Breast cancer cells induce stromal fibroblasts to express MMP-9 via secretion of TNF- $\alpha$ and TGF- $\beta$," Journal of Cell Science, vol. 118, no. 10, pp. 2143-2153, 2005.

[171] N. Erez, M. Truitt, P. Olson, and D. Hanahan, " Cancer Associated Fibroblasts are activated in incipient neoplasia to orchestrate tumor-promoting inflammation in an NF- $\kappa$ Bdependent manner," Cancer Cell, vol. 17, no. 2, pp. 135-147, 2010.

[172] K. Pietras and A. Östman, "Hallmarks of cancer: interactions with the tumor stroma," Experimental Cell Research, vol. 316, no. 8, pp. 1324-1331, 2010.

[173] R. Kalluri and M. Zeisberg, "Fibroblasts in cancer," Nature Reviews Cancer, vol. 6, no. 5, pp. 392-401, 2006.
[174] M. Snyder, X.-Y. Huang, and J. J. Zhang, "Signal Transducers and Activators of Transcription 3 (STAT3) directly regulates cytokine-induced fascin expression and is required for breast cancer cell migration," Journal of Biological Chemistry, vol. 286, no. 45, pp. 38886-38893, 2011.

[175] I. Barbieri, S. Pensa, T. Pannellini et al., "Constitutively active Stat3 enhances neu-mediated migration and metastasis in mammary tumors via upregulation of Cten," Cancer Research, vol. 70, no. 6, pp. 2558-2567, 2010.

[176] D. J. Prockop, "Marrow stromal cells as stem cells for nonhematopoietic tissues," Science, vol. 276, no. 5309, pp. 71-74, 1997.

[177] S. Maxson, E. A. Lopez, D. Yoo, A. Danilkovitch-Miagkova, and M. A. LeRoux, "Concise review: role of mesenchymal stem cells in wound repair," Stem Cells Translational Medicine, vol. 1, no. 2, pp. 142-149, 2012.

[178] E. Spaeth, A. Klopp, J. Dembinski, M. Andreeff, and F. Marini, "Inflammation and tumor microenvironments: defining the migratory itinerary of mesenchymal stem cells," Gene Therapy, vol. 15, no. 10, pp. 730-738, 2008.

[179] Y. Rattigan, J.-M. Hsu, P. J. Mishra, J. Glod, and D. Banerjee, "Interleukin 6 mediated recruitment of mesenchymal stem cells to the hypoxic tumor milieu," Experimental Cell Research, vol. 316, no. 20, pp. 3417-3424, 2010.

[180] E. Ritter, A. Perry, J. Yu, T. Wang, L. Tang, and E. Bieberich, "Breast cancer cell-derived fibroblast growth factor 2 and vascular endothelial growth factor are chemoattractants for bone marrow stromal stem cells," Annals of Surgery, vol. 247, no. 2, pp. 310-314, 2008.

[181] R. M. Dwyer, S. M. Potter-Beirne, K. A. Harrington et al., "Monocyte chemotactic protein-1 secreted by primary breast tumors stimulates migration of mesenchymal stem cells," Clinical Cancer Research, vol. 13, no. 17, pp. 5020-5027, 2007.

[182] Y. Zhang, P. Yang, T. Sun et al., "MiR-126 and miR-126* repress recruitment of mesenchymal stem cells and inflammatory monocytes to inhibit breast cancer metastasis," Nature Cell Biology, vol. 15, no. 3, pp. 284-294, 2013.

[183] R. Lotfi, J. Eisenbacher, G. Solgi et al., "Human mesenchymal stem cells respond to native but not oxidized damage associated molecular pattern molecules from necrotic (tumor) material," European Journal of Immunology, vol. 41, no. 7, pp. 2021-2028, 2011.

[184] A. H. Klopp, E. L. Spaeth, J. L. Dembinski et al., “Tumor irradiation increases the recruitment of circulating mesenchymal stem cells into the tumor microenvironment," Cancer Research, vol. 67, no. 24, pp. 11687-11695, 2007.

[185] P. Chaturvedi, D. M. Gilkes, C. C. Wong et al., "Hypoxiainducible factor-dependent breast cancer-mesenchymal stem cell bidirectional signaling promotes metastasis," Journal of Clinical Investigation, vol. 123, no. 1, pp. 189-205, 2013.

[186] S. Kidd, E. Spaeth, K. Watson et al., "Origins of the tumor microenvironment: quantitative assessment of adipose-derived and bone marrow-derived stroma," PLoS ONE, vol. 7, no. 2, Article ID e30563, 2012.

[187] T. Zhang, Y. W. Lee, Y. F. Rui, T. Y. Cheng, X. H. Jiang, and $\mathrm{G}$. Li, "Bone marrow-derived mesenchymal stem cells promote growth and angiogenesis of breast and prostate tumors," Stem Cell Research and Therapy, vol. 4, no. 3, article 70, 2013.

[188] J. M. Ryan, F. P. Barry, J. M. Murphy, and B. P. Mahon, "Mesenchymal stem cells avoid allogeneic rejection," Journal of Inflammation, vol. 2, article 8, 2005. 
[189] S. A. Patel, J. R. Meyer, S. J. Greco, K. E. Corcoran, M. Bryan, and P. Rameshwar, "Mesenchymal stem cells protect breast cancer cells through regulatory T cells: role of mesenchymal stem cellderived TGF- $\beta$," Journal of Immunology, vol. 184, no. 10, pp. 5885-5894, 2010.

[190] R. S. Waterman, S. L. Tomchuck, S. L. Henkle, and A. M. Betancourt, "A new mesenchymal stem cell (MSC) paradigm: polarization into a pro-inflammatory $\mathrm{MSC1}$ or an immunosuppressive MSC2 phenotype," PLoS ONE, vol. 5, no. 4, Article ID e10088, 2010.

[191] J. Lei, Z. Wang, D. Hui et al., "Ligation of TLR2 and TLR4 on murine bonTritschler I.e marrow-derived mesenchymal stem cells triggers differential effects on their immunosuppressive activity," Cellular Immunology, vol. 271, no. 1, pp. 147-156, 2011.

[192] M. Pevsner-Fischer, V. Morad, M. Cohen-Sfady et al., "Tolllike receptors and their ligands control mesenchymal stem cell functions," Blood, vol. 109, no. 4, pp. 1422-1432, 2007.

[193] S. Liu, C. Ginestier, S. J. Ou et al., "Breast cancer stem cells are regulated by mesenchymal stem cells through cytokine networks," Cancer Research, vol. 71, no. 2, pp. 614-624, 2011.

[194] H.-J. Li, F. Reinhardt, H. R. Herschman, and R. A. Weinberg, "Cancer-stimulated mesenchymal stem cells create a carcinoma stem cell niche via prostaglandin E2 Signaling," Cancer Discovery, vol. 2, no. 9, pp. 840-855, 2012.

[195] X.-L. Yan, C.-J. Fu, L. Chen et al., "Mesenchymal stem cells from primary breast cancer tissue promote cancer proliferation and enhance mammosphere formation partially via EGF/EGFR/Akt pathway," Breast Cancer Research and Treatment, vol. 132, no. 1, pp. 153-164, 2012.

[196] E. Devarajan, Y.-H. Song, S. Krishnappa, and E. Alt, "Epithelialmesenchymal transition in breast cancer lines is mediated through PDGF-D released by tissue-resident stem cells," International Journal of Cancer, vol. 131, no. 5, pp. 1023-1031, 2012.

[197] Q. Xu, L. Wang, H. Li et al., "Mesenchymal stem cells play a potential role in regulating the establishment and maintenance of epithelial-mesenchymal transition in MCF7 human breast cancer cells by paracrine and induced autocrine TGF- $\beta$," International Journal of Oncology, vol. 41, no. 3, pp. 959-968, 2012.

[198] A. De Luca, L. Lamura, M. Gallo, V. Maffia, and N. Normanno, "Mesenchymal stem cell-derived interleukin-6 and vascular endothelial growth factor promote breast cancer cell migration," Journal of Cellular Biochemistry, vol. 113, no. 11, pp. 3363-3370, 2012.

[199] A. E. Karnoub, A. B. Dash, A. P. Vo et al., "Mesenchymal stem cells within tumour stroma promote breast cancer metastasis," Nature, vol. 449, no. 7162, pp. 557-563, 2007.

[200] J. L. Halpern, A. Kilbarger, and C. C. Lynch, "Mesenchymal stem cells promote mammary cancer cell migration in vitro via the CXCR2 receptor," Cancer Letters, vol. 308, no. 1, pp. 91-99, 2011.

[201] S. Y. Shin, J.-S. Nam, Y. Lim, and Y. H. Lee, “TNF $\alpha$-exposed bone marrow-derived mesenchymal stem cells promote locomotion of MDA-MB-231 breast cancer cells through transcriptional activation of CXCR3 ligand chemokines," Journal of Biological Chemistry, vol. 285, no. 40, pp. 30731-30740, 2010.

[202] L. V. Rhodes, J. W. Antoon, S. E. Muir, S. Elliott, B. S. Beckman, and M. E. Burow, "Effects of human mesenchymal stem cells on ER-positive human breast carcinoma cells mediated through ER-SDF-1/CXCR4 crosstalk," Molecular Cancer, vol. 9, article $295,2010$.
[203] M. Studeny, F. C. Marini, J. L. Dembinski et al., "Mesenchymal stem cells: potential precursors for tumor stroma and targeteddelivery vehicles for anticancer agents," Journal of the National Cancer Institute, vol. 96, no. 21, pp. 1593-1603, 2004.

[204] X.-C. Chen, R. Wang, X. Zhao et al., "Prophylaxis against carcinogenesis in three kinds of unestablished tumor models via IL12-gene-engineered MSCs," Carcinogenesis, vol. 27, no. 12, pp. 2434-2441, 2006.

[205] M. R. Loebinger, A. Eddaoudi, D. Davies, and S. M. Janes, "Mesenchymal stem cell delivery of TRAIL can eliminate metastatic cancer," Cancer Research, vol. 69, no. 10, pp. 41344142, 2009.

[206] L. Kucerova, V. Altanerova, M. Matuskova, S. Tyciakova, and C. Altaner, "Adipose tissue-derived human mesenchymal stem cells mediated prodrug cancer gene therapy," Cancer Research, vol. 67, no. 13, pp. 6304-6313, 2007.

[207] N. Serakinci, U. Fahrioglu, and R. Christensen, "Mesenchymal stem cells, cancer challenges and new directions," European Journal of Cancer, vol. 50, no. 8, pp. 1522-1530, 2014. 


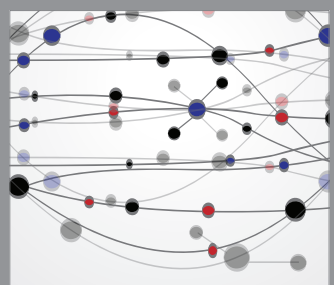

The Scientific World Journal
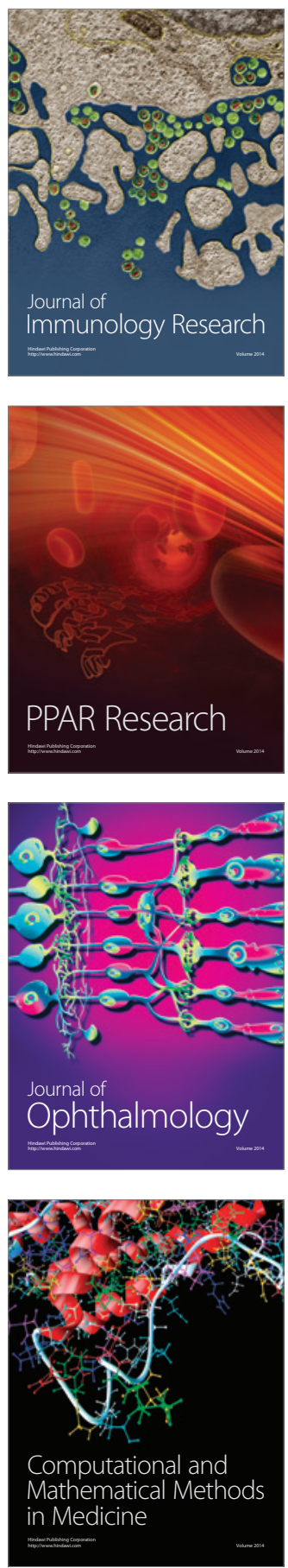

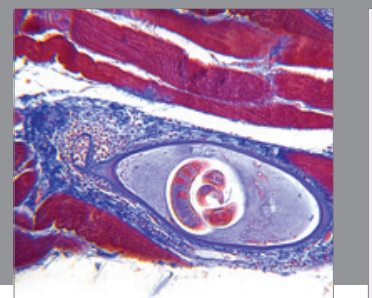

Gastroenterology

Research and Practice
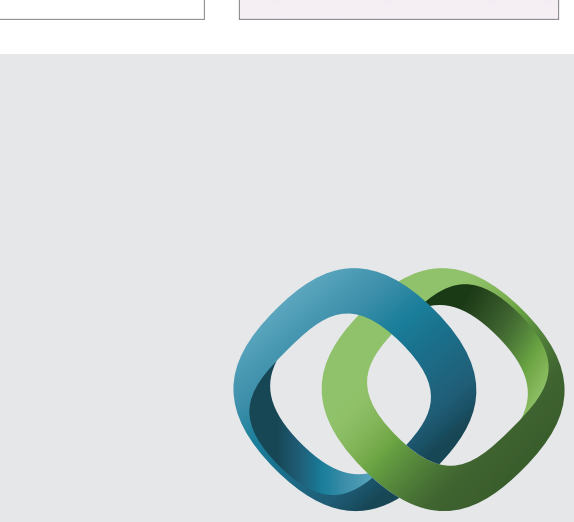

\section{Hindawi}

Submit your manuscripts at

http://www.hindawi.com
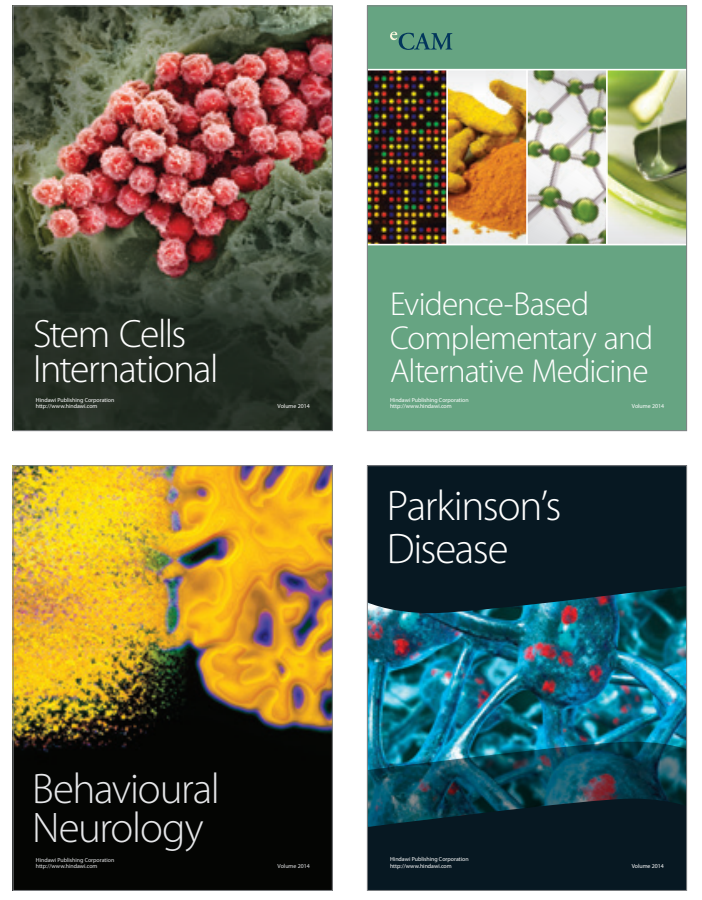
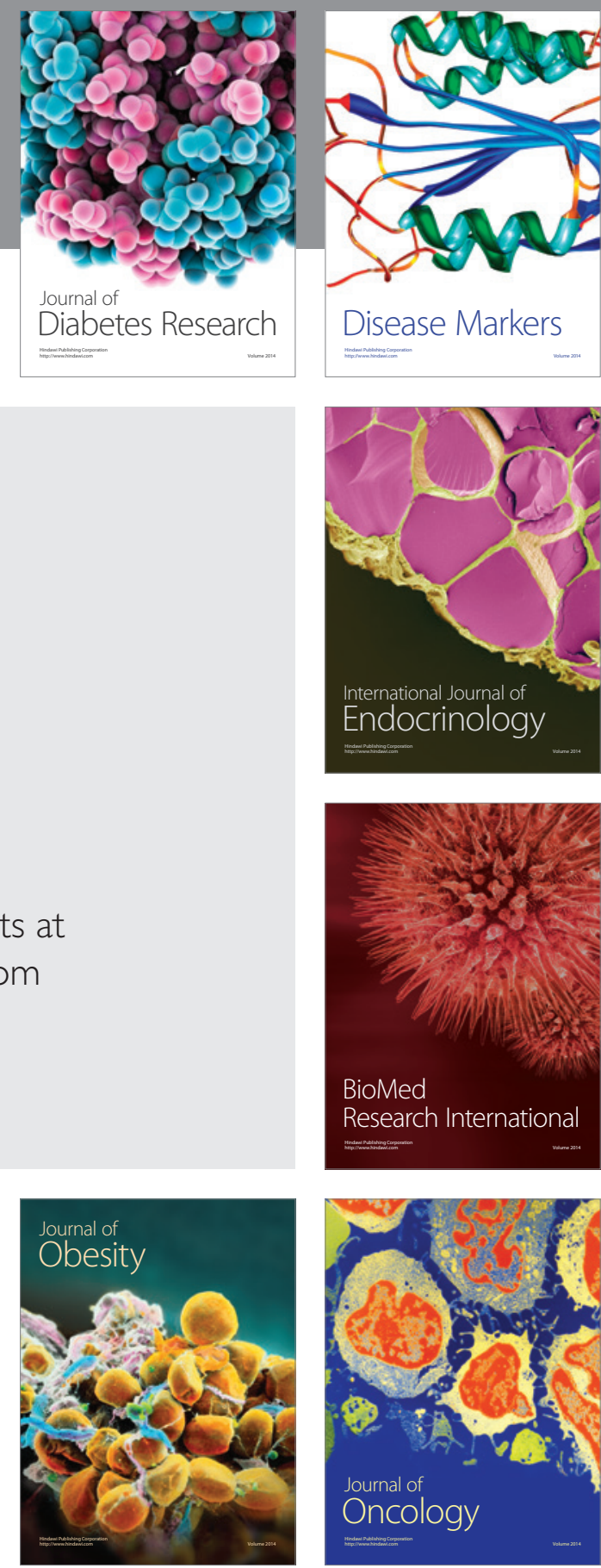

Disease Markers
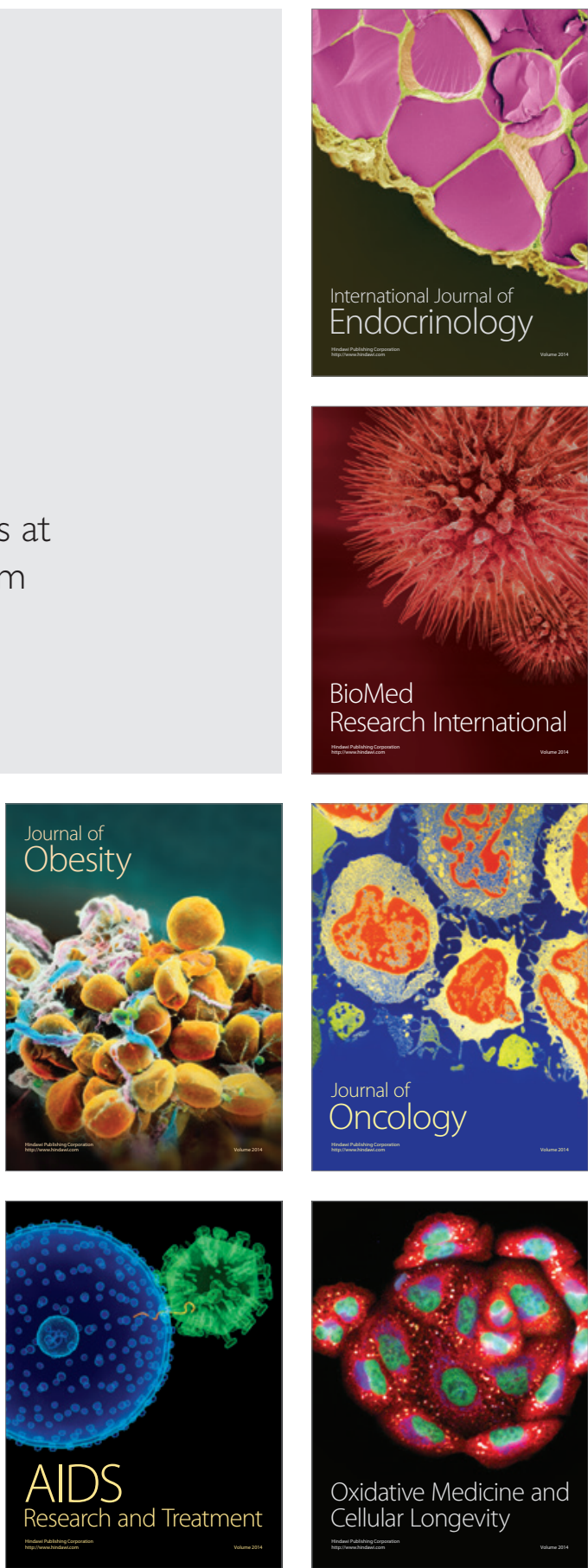